\title{
An experimental study on Sodalite and SAP matrices for immobilization of spent chloride salt waste
}

\author{
Francesca Giacobbo ${ }^{\text {a, }}$, Mirko Da Ros ${ }^{\text {a }}$, Elena Macerata ${ }^{\mathrm{a}}$, Mario Mariani ${ }^{\mathrm{a}}$, Marco Giola ${ }^{\mathrm{a}}$, \\ Giorgio De Angelis ${ }^{b}$, Mauro Capone ${ }^{c}$, Carlo Fedeli ${ }^{c}$
}

a Politecnico di Milano, Dipartimento di Energia, Sezione Ingegneria Nucleare, Piazza L. da Vinci 32, 20133 Milano, Italy

${ }^{\mathrm{b}}$ Retired from ENEA, CR Casaccia, Unità Tecnica Tecnologie e Impianti per La Fissione e La Gestione Del Materiale Nucleare, Via Anguillarese 301, 00123 S. Maria di Galeria, Roma, Italy

${ }^{\mathrm{c}}$ ENEA, CR Casaccia, Dipartimento Fusione e Tecnologie per La Sicurezza Nucleare, Via Anguillarese 301, 00123 S. Maria di Galeria, Roma, Italy

\begin{abstract}
In the frame of Generation IV reactors a renewed interest in pyro-processing of spent nuclear fuel is underway. Molten chloride salt waste arising from the recovering of uranium and plutonium through pyro-processing is one of the problematic wastes for direct application of vitrification or ceramization. In this work, Sodalite and SAP have been evaluated and compared as potential matrices for confinement of spent chloride salt waste coming from pyroprocessing. To this aim Sodalite and SAP were synthesized both in pure form and mixed with different glass matrices, i.e. commercially available glass frit and borosilicate glass. The confining matrices were loaded with mixed chloride salts to study their retention capacities with respect to the elements of interest. The matrices were characterized and leached for contact times up to 150 days at room temperature and at $90{ }^{\circ} \mathrm{C}$. SEM analyses were also performed in order to compare the matrix surface before and after leaching. Leaching results are discussed and compared in terms of normalized releases with similar results reported in literature. According to this comparative study the SAP matrix with glass frit binder resulted in the best matrix among the ones studied, with respect to retention capacities for both matrix and spent fuel elements.
\end{abstract}

\section{Introduction}

The recovering of energy-producing elements such as uranium and plutonium from spent nuclear fuel, which is in line with Generation IV reactors concept, can be performed by pyro-chemical processing [1,2]. According to a procedure developed by the

* Corresponding author. Nuclear Engineering Section, Department of Energy, Politecnico di Milano, Via La Masa 34, 20133 Milan, Italy.

E-mail address: francesca.giacobbo@polimi.it (F. Giacobbo).
Argonne National Laboratory, the actinides and fission products are extracted by electrodeposition in a molten chloride salt medium ( $\mathrm{LiCl}-\mathrm{KCl}, 59-41 \mathrm{~mol} \%$ eutectic composition) at $500{ }^{\circ} \mathrm{C}[3-5]$. This process generates chloride salt wastes contaminated by fission products, containing alkali-metals and alkaline-earths, such as Cs, $\mathrm{Ba}, \mathrm{Sr}$ and some rare-earths. The so obtained molten salt waste, which mainly consists of metal chlorides, cannot be subjected to conventional solidification processes, such as vitrification and ceramization, due to chloride volatility and low compatibility with silicate glass [6].

Therefore, in order to condition chloride salt waste coming from 
pyro-processes different methods and immobilization matrices have been considered and assessed for their leaching behavior and their capacity for retention of volatile elements [7,8]. Two possible alternatives can be adopted to manage this kind of waste: i) development of specific ceramic matrices such as mineral phases capable of immobilizing chlorides or ii) dechlorination of the fission products to allow incorporation into glass [9].

Processing of ceramic waste forms with the aim at confining chloride salt wastes coming from pyro-processes can be performed at high temperatures (up to $850{ }^{\circ} \mathrm{C}$ ) and under high pressures (up to $25000 \mathrm{psi}$ ) according to a procedure named hot isostatic pressing (HIP) [10-14]. More recently, an alternative procedure for processing ceramic waste forms under ambient pressure, called Pressureless Consolidation (PC) was developed at the Idaho National Laboratory $[12,15]$.

Sodalite, a naturally occurring aluminosilicate mineral containing chlorine, is among those mineral phases considered as potential immobilization matrices for chloride salt wastes [16,17]. Various synthesis methods to obtain sodalite-based matrices have been developed and optimized, i.e. starting from Zeolite 4A (used for preliminary decontamination of the salt by ion-exchange) $[18,19]$ or direct synthesis from silica and sodium aluminate re-agents [20] or from kaolinite through metakaolinite and nepheline $[15,21,22]$. Some authors of the present work compared two different methods to synthesize sodalite in order to condition the chloride salt waste: i) starting from kaolinite through nepheline and ii) starting directly from silica and sodium aluminate. The ob-tained products were fully characterized in order to determine the best synthesis method. The characterization tests revealed that synthesis from kaolinite through nepheline was by far the best synthesis method, with a high yield of sodalite, provided that rigorous conditions are followed. In particular, the preparation of pellets of reagents under argon atmosphere, followed by heating at $800{ }^{\circ} \mathrm{C}$ in an oven for not less than $100 \mathrm{~h}$, is necessary to obtain a good product [22].

Past research activities were also conducted by the present authors to demonstrate the feasibility of sodalite synthesis, from kaolinite through nepheline, via the Pressureless Consolidation (PC) process proposed by Idaho National Laboratory [15,23]. Moreover, characterization and leaching studies were performed both on pellets and powders of sodalite blended with glass [19,23-26].

The Korea Atomic Energy Research Institute (KAERI) proposed an immobilization matrix for chloride salt wastes, termed SAP, consisting of $\mathrm{SiO}_{2}, \mathrm{Al}_{2} \mathrm{O}_{3}$ and $\mathrm{P}_{2} \mathrm{O}_{5}[27,28]$. This matrix, synthesized by a conventional sol-gel process, is able to stabilize volatile salt wastes due to the formation of metal aluminosilicates, aluminophosphates and phosphates, generating chlorine gas [29]. Glass can be added to the SAP matrix as a chemical binder giving rise to higher disposal efficiency and to a lower volume of waste compared with other immobilization matrices [27,30]. A recent evolution of SAP, the glassy wasteform U-SAP, shows even better performances with respect to other SAP wasteforms [31,32].

The present paper illustrates and summarizes the research activities performed by the present authors, focused on a feasibility study regarding Sodalite and SAP ceramic wasteforms for conditioning chloride salt waste and compares experimental leaching results with results from the literature regarding similar wasteforms. To this end, Sodalite and SAP were synthetized and characterized both in pure form and mixed with different glass matrices, i.e. commercially available glass frit and borosilicate glass. The confining matrices were loaded with chloride salt wastes in order to study their retention capacities with respect to the elements of interest. To achieve this, leaching tests at different temperatures were performed up to 150 days in order to systematically study the behavior of the obtained Sodalite and SAP based matrices. Collected data were then analyzed and compared, in terms of normalized releases after 7 days at $90{ }^{\circ} \mathrm{C}$, with similar leaching results from the literature.

The paper is organized as follows: the second section 'Experimental' briefly describes the synthesis conditions, matrix preparations and characteristics of the performed leaching tests and of the parameters adopted to quantify leaching behavior. Characterization and leaching results obtained in this work are reported in Section 3. In Section 4 'Discussion' the normalized release values measured in this study are compared with equivalent literature results and discussed. Finally, Section 5 concludes the paper.

\section{Experimental}

\subsection{Matrix synthesis}

\subsubsection{Sodalite-based matrices}

Several sodalite $\left(\mathrm{Na}_{6}(\mathrm{Li}, \mathrm{K})_{2}\left[\left(\mathrm{AlO}_{2}\right)_{6}\left(\mathrm{SiO}_{2}\right)_{6}\right] \mathrm{Cl}_{2}\right)$ samples were prepared according to a two-step synthesis, through nepheline $\left(\mathrm{NaAlSiO}_{4}\right)$ from kaolinite $\left(\mathrm{Al}_{2} \mathrm{Si}_{2} \mathrm{O}_{7}\right)$, previously tested and optimized by some of the present authors [22,23]. Sodalite based matrices blended with glass were prepared by mixing and milling at room temperature the following reagents in the reported proportions in weight: $66.3 \%$ nepheline (NE), $25.0 \%$ glass and $8.7 \%$ simulated chloride salt waste (CSW). The simulated chloride salts were composed of lithium and potassium chlorides (eutectic composition) and a mixture of chloride salts of Rb, $\mathrm{Sr}, \mathrm{Cs}, \mathrm{Ba}, \mathrm{La}$ and Nd (Table 1). The powder samples, kept under slight pressure, were introduced into a furnace and treated at $500{ }^{\circ} \mathrm{C}$ for $1 \mathrm{~h}$ in order to allow any residual moisture to evaporate, and then kept at $925^{\circ} \mathrm{C}$ for $7 \mathrm{~h}[1,23]$. Two series of samples were prepared with two different types of glass, namely commercially available glass frit (GF) and borosilicate glass (BG) (Table 2). The so-obtained sodalitebased matrices were fully characterized by X-ray diffraction, FT-IR, SEM-EDS and thermogravimetric analyses and results have already been reported in literature [22-24]. In the following discussion sodalite samples are indicated with the abbreviation SOD, while the sodalite samples blended with glass frit (GF) or borosilicate glass (BG) and loaded with chloride salt waste (CSW) are indicated as CSW.SOD.GF and CSW.SOD.BG, respectively.

\subsubsection{SAP-based matrices}

SAP matrix, $\mathrm{SiO}_{2}-\mathrm{Al}_{2} \mathrm{O}_{3}-\mathrm{P}_{2} \mathrm{O}_{5}$, was synthesized by a conventional sol-gel process developed by Korea Atomic Energy Research Institute $[25,27-29,33]$. The so-obtained SAP was reacted with lithium and potassium chlorides in the eutectic composition (LiKCl.SAP) in the salt/SAP ratio of 1:2, 1:3 and 1:4, at increasing temperatures

\section{Table 1}

Composition of the simulated chloride salt waste loadings.

\begin{tabular}{|c|c|c|c|c|}
\hline \multirow[t]{2}{*}{ Chloride } & $\begin{array}{l}\text { CSW.SOD.GF } \\
\text { CSW.SOD.BG }\end{array}$ & CSW.SAP & $\begin{array}{l}\text { CSW.SAP.GF } \\
\text { CSW.SAP.BG1 } \\
\text { CSW.SAP.BG2 }\end{array}$ & LiKCl.SAP.BG \\
\hline & Wt\% & Wt\% & $\mathrm{Wt} \%$ & $\mathrm{Wt} \%$ \\
\hline $\mathrm{LiCl}+\mathrm{KCl}$ & 7.802 & 29.50 & 20.65 & 23.33 \\
\hline $\mathrm{RbCl}$ & 0.066 & 0.167 & 0.117 & \\
\hline $\mathrm{CsCl}$ & 0.066 & 0.833 & 0.583 & \\
\hline $\mathrm{SrCl}_{2}$ & 0.066 & 0.167 & 0.117 & \\
\hline $\mathrm{BaCl}_{2}$ & 0.066 & 0.333 & 0.233 & \\
\hline $\mathrm{LaCl}_{3}$ & 0.301 & 0.333 & 0.233 & \\
\hline $\mathrm{NdCl}_{3}$ & 0.301 & 1.000 & 0.699 & \\
\hline $\mathrm{CeCl}_{3}$ & & 0.667 & 0.466 & \\
\hline $\mathrm{PrCl}_{3}$ & & 0.333 & 0.233 & \\
\hline Total & 8.668 & 33.33 & 23.33 & 23.33 \\
\hline
\end{tabular}


Table 2

Composition of glass powders.

\begin{tabular}{lllll}
\hline Borosilicate glass & & & Glass frit \\
\cline { 5 - 5 } Component & $\mathrm{Wt} \%$ & & Component & $\mathrm{Wt} \%$ \\
\hline $\mathrm{Al}_{2} \mathrm{O}_{3}$ & 7.5 & $\mathrm{Al}_{2} \mathrm{O}_{3}$ & 2.0 \\
$\mathrm{~B}_{2} \mathrm{O}_{3}$ & 19.3 & $\mathrm{CaO}$ & 11.5 \\
$\mathrm{CaO}$ & 1.3 & $\mathrm{Fe}_{2} \mathrm{O}_{3}$ & 0.23 \\
$\mathrm{~K}_{2} \mathrm{O}$ & 0.4 & $\mathrm{~K}_{2} \mathrm{O}$ & 2.0 \\
$\mathrm{Li}_{2} \mathrm{O}$ & 0.0 & $\mathrm{MgO}_{2}$ & 2.0 \\
$\mathrm{Na}_{2} \mathrm{O}$ & 6.5 & $\mathrm{Na}_{2} \mathrm{O}$ & 13.0 \\
$\mathrm{SiO}_{2}$ & 63.1 & $\mathrm{SiO}_{2}$ & 71.3 \\
\hline
\end{tabular}

$\left(550-1000^{\circ} \mathrm{C}\right)$ and reaction times $(5-30 \mathrm{~h})$ in order to optimize the synthesis. Some matrices were prepared with SAP and CSW (salt/ SAP ratio of $1: 2$ corresponding to $33.33 \%$ in weight of chlorides) at $950{ }^{\circ} \mathrm{C}$ for $30 \mathrm{~h}$, obtaining the CSW.SAP samples. A weight loss of about $18 \%$ was observed due to volatilization of $90 \%$ of the initial $\mathrm{Cl}$ content, consistently with the dechlorination process inherent in the SAP based immobilization procedure [27]. In some cases to the samples obtained with the salt/SAP ratio of $1: 2$ glass frit or borosilicate glass were added in the sample/glass ratio 70:30 and the powders were treated at $1150{ }^{\circ} \mathrm{C}$ at ambient pressure giving the final ceramic waste forms loaded with $23.33 \%$ in weight of chlorides, indicated in the following with CSW.SAP.GF and CSW.SAP.BG, respectively. An attempt was also made to optimize the reaction time: from sample CSW.SAP.BG1 to CSW.SAP.BG2 the reaction time was increased from $1 \mathrm{~h}$ (CSW.SAP.BG1) to $4 \mathrm{~h}$ (CSW.SAP.BG2). Samples of SAP with chloride salts (23.33\% in weight) composed of lithium and potassium chlorides in the eutectic composition (LiKCl.SAP.BG) were also prepared. The compositions of the simulated chloride salt waste and of the two types of glass are reported in Tables 1 and 2

\subsection{Characterization}

The so-obtained SOD- and SAP-based matrices were characterized by density measurements, X-ray diffraction with a Bruker AXS D8 ADVANCE diffractometer employing a $\mathrm{Cu}-\mathrm{K} \alpha$ radiation $(\lambda=1.5418 \AA$ ) and by Fourier-transform infrared spectroscopy on a Perkin Elmer FT1600 analyzer. Moreover, SEM-EDS and thermogravimetric analyses were performed in order to assess the nature of the matrices before the leaching tests $[25,29]$. Finally, SEM analyses were also carried out on powder before and after leaching tests by a Zeiss Supra 40 microscope equipped with a GEMINI column $(\mathrm{EHT}=2-3 \mathrm{kV})$.

\subsection{Leaching tests}

Several leaching tests under static conditions were performed according to the Product Consistency Test (PCT) for contact times up to 150 days at two different temperatures $\left(23^{\circ} \mathrm{C}\right.$ and $\left.90{ }^{\circ} \mathrm{C}\right)$ [34] on samples of both matrices loaded with CSW and blended with glass. In some cases, pure matrix or matrices without glass were leached to help result interpretation.

The tests were performed in pre-cleaned PTFE bottles $(150 \mathrm{~mL})$. The sample test bottle containing $1 \mathrm{~g}$ of matrix powder in $20 \mathrm{~mL}$ of ultrapure water and the reference test bottle containing $20 \mathrm{~mL}$ of ultrapure water (blank), were both stored at the desired temperature and contact time. Each sample test bottle was weighed before and after the test in order to verify that the mass loss was not greater than $5 \%$ of the original leachant mass. At the end of the contact time the liquid phase was separated from the solid phase and subdivided into two fractions. One fraction was used for the $\mathrm{pH}$ measurement. The other aliquot, previously filtered by $0.45 \mu \mathrm{m}$ polyethersulfone (PES) SUPOR membrane and suitably diluted in $1 \%$ ultrapure nitric acid, was analyzed by Thermo Fisher X-Series II ICP-MS calibrated in the range $0-100 \mu \mathrm{g} / \mathrm{L}$. The measured concentrations of the elements present in the leachate were corrected by subtracting the measured background concentration of the blank samples and taking into account also weight losses in terms of final volumes according to the ASTM calculation procedure. During the leaching tests the $\mathrm{pH}$ was not buffered. The fraction of each element in the un-leached sodalite based sample was estimated according to the ideal sodalite formula, i.e. $\mathrm{Na}_{6} \mathrm{Li}_{1,16} \mathrm{~K}_{0,84} \mathrm{~A}$ $1_{6} \mathrm{O}_{24} \mathrm{Si}_{6} \mathrm{Cl}_{2}$ with molecular weight $964.113 \mathrm{~g} \mathrm{~mol}^{-1}$ and according to the ideal SAP formula, i.e. $\mathrm{SiO}_{2}-\mathrm{Al}_{2} \mathrm{O}_{3}-\mathrm{P}_{2} \mathrm{O}_{5}$ with molecular weight $303.99 \mathrm{~g} \mathrm{~mol}^{-1}$. The element release from the matrices is described in terms of normalized release $N L_{i}\left(\mathrm{~g} \cdot \mathrm{m}^{-2}\right)$ and "integrated" normalized release rate $N R_{i}\left(\mathrm{~g} \cdot \mathrm{m}^{-2} \cdot \mathrm{day}^{-1}\right)$ for ' $i$ ' element, defined according to the expressions 1 and 2 , respectively:

$$
\begin{aligned}
N L_{i} & =\frac{c_{i}}{f_{i} \cdot(S A / V)} \\
N R_{i} & =\frac{c_{i}}{f_{i} \cdot(S A / V) \cdot t}
\end{aligned}
$$

where $c_{i}(\mathrm{~g} / \mathrm{L})$ is the concentration of $i$ element in the leachate; $f_{i}$ the fraction of $i$ element in the unleached waste matrix sample (unitless); $S A / V\left(\mathrm{~m}^{2} / \mathrm{L}\right)$ is the ratio of surface area of the waste matrix sample and the leachate volume; $t$ the time duration of test in days. The data obtained were also analyzed in terms of percentage of release $R(t)_{i}$ of each $i$ element vs. time:

$$
R(t)_{i}=\frac{a_{i, t}}{a_{i, o}} \cdot 100
$$

where $a_{i, t}$ corresponds to the mass of the $i$ element leached at time $t$ and $a_{i, 0}$ is the mass of the $i$ element initially present in the sample.

The surface area SA of each powder sample was estimated according to the example calculation of the exposed glass waste form surface area reported in Appendix X1 of the ASTM C1285-02 [34]. To this aim, the particle shape was assumed spherical with a diameter equal to the average value of the particle size distribution, and the density value was measured by helium pycnometry. For all powder samples the particle size distribution was $6.3 \cdot 10^{-5}$ to $1.25 \cdot 10^{-4} \mathrm{~m}$ and the assumed mean diameter was $9.40 \cdot 10^{-5} \mathrm{~m}$. Densities and SA/V ratios data assumed for the samples under study are reported in the Supplementary Information (Table SI1). In the case of SAP based samples, normalized releases have been evaluated taking into account gaseous chlorine loss.

\section{Results}

\subsection{X-ray diffraction characterization}

\subsubsection{Sodalite-based samples}

The present authors have already reported about the characterization of SOD-based matrices loaded with CSW and blended with glass according to the here described synthetic route. The previous work was dedicated to the optimization of the synthetic procedure. XRD analyses of CSW.SOD.GF samples prepared at 800 , 850 and $925^{\circ} \mathrm{C}$ were performed in order to optimize the temperature of the thermal treatment. The XRD spectra of samples at 800 and $850{ }^{\circ} \mathrm{C}$ showed the presence of a main phase similar to sodalite (JCPDS card 37-0476) with a small shift of about 0.5 deg and traces of nepheline. The effect of the heating time was also considered. XRD analyses of the Na.SOD.GF samples obtained after 1, 3 and $7 \mathrm{~h}$ of heat treatment at $925{ }^{\circ} \mathrm{C}$ highlighted that the samples contain 
sodalite (JCPDS card 88-2086, very similar to JCPDS card 37-476) with decreasing amount of nepheline (JCPDS card 76-2469) and sodium chloride (JCPDS card 5-628) at increasing heating time. Fig. 1 clearly shows that the XRD spectrum of CSW.SOD.GF obtained at $925{ }^{\circ} \mathrm{C}$ after $7 \mathrm{~h}$ well correspond to the sodalite phase. The same conclusion was confirmed by FT-IR analyses of CSW.SOD.GF that showed the presence of the characteristic peaks of sodalite [25].

Therefore, a thermal treatment of $7 \mathrm{~h}$ at $925^{\circ} \mathrm{C}$ was identified as effective in obtaining a final product essentially composed of sodalite (JCPDS card 37-0476). In general, the final waste form shows a density of $2.382 \mathrm{~g} / \mathrm{cm}^{3}$, satisfactory if compared with pure sodalite $\left(2.1-2.3 \mathrm{~g} / \mathrm{cm}^{3}\right)$, and is characterized by the absence of microcracks and macroporosity. Similarly, XRD (Fig. 2) and FTIR analyses of CSW.SOD.BG indicates the formation of sodalite (JCPDS card 79-0091) with possible traces of halite ( $\mathrm{NaCl}$, JCPDS card 5-628).

In order to better investigate the feasibility of incorporating some fission products as cations in sodalite phases, several samples were prepared starting from a mixture of $\mathrm{NaCl} / \mathrm{CsCl}, \mathrm{NaCl} / \mathrm{SrCl}_{2}$ and $\mathrm{NaCl} / \mathrm{NdCl}_{3}$ with a Cs, Sr, and $\mathrm{Nd}$ content ranging from 25 to $100 \%$, according to the experimental conditions previously optimized (all the reagents were accurately mixed, finely ground, pelletized, and treated at $925{ }^{\circ} \mathrm{C}$ for $7 \mathrm{~h}$ ). The samples obtained are indicated as 100X.SOD, 50X.SOD and 25X.SOD where $\mathrm{X}=\mathrm{Cs}$, Sr, or Nd.

As far as the samples 100Cs.SOD, 50Cs.SOD and 25Cs.SOD are concerned, by the comparison with an XRD spectral library, the main phases identified in all the samples were sodalite $\left(\mathrm{Na}_{4} \mathrm{Al}_{3}\right.$ $\mathrm{Si}_{3} \mathrm{O}_{12} \mathrm{Cl}$, JCPDS card 37-476) and pollucite ((Cs,Na)AlSi $\mathrm{O}_{6}$, JCPDS card 15-317). Considering the main peak of sodalite phase at $2 \theta$ of $24.54^{\circ}$, the XRD spectrum of the sample 50Cs.SOD showed the best agreement with the sodalite phase. At lower Cs content a clearly visible shift of the peak is observed, while at higher Cs content the shift is much less marked, suggesting the incorporation of the cation in the sodalite structure. Moreover, the intensity of the main peak decreases with the increase of the Cs content. Similar considerations can be made for the pollucite phase. Considering one of the main peaks of the pollucite phase $\left(2 \theta=26.10^{\circ}\right)$, once again the best agreement was obtained in the sample 50Cs.SOD, while in the other samples a shift and an intensity increase of the peak is observed with the increase of the Cs content. Moreover, in all the samples there are some unidentified peaks in the region
$2 \theta=20-30^{\circ}$. The XRD analyses of the SOD samples containing $\mathrm{Sr}$ showed that the main phase present in all the samples is sodalite (JCPDS card 37-476). In particular, the XRD spectrum of the sample 25Sr.SOD showed the best agreement with the sodalite phase, while in the samples with higher $\mathrm{Sr}$ content a shift of the signal was observed suggesting the incorporation of the cation in the sodalite structure. Moreover, in all the samples traces of nepheline (JCPDS card 83-2279) and some other peaks at $2 \theta$ around $22^{\circ}$ and $27.5-28.5^{\circ}$ not yet identified were observed. It is noted that some signals of the nepheline phase decrease with increasing the $\mathrm{Sr}$ percentage, while some other showed a little shift towards lower $2 \theta$ values, suggesting the formation of a Sr-containing nepheline phase.

As far as the samples $100 \mathrm{Nd}$.SOD, 50Nd.SOD and 25Nd.SOD are concerned, by the comparison with an XRD spectral library, the main phases identified in all the samples were sodalite (JCPDS card 37-476), nepheline ( $\mathrm{K}_{0.24} \mathrm{Na}_{6} \mathrm{Al}_{6.24} \mathrm{Si}_{9.76} \mathrm{O}_{32}$, JCPDS card 83-2279) and calcium neodymium oxide silicate $\left(\mathrm{Ca}_{2} \mathrm{Nd}_{8}\left(\mathrm{SiO}_{4}\right)_{6} \mathrm{O}_{2}\right.$, JCPDS card 78-1038). In particular, with the decreasing of the Nd content in the sample the main peak of the sodalite phase at $2 \theta$ of $24.54^{\circ}$ shifts to lower angles and increases in intensity. The main peak of the calcium neodymium oxide silicate, found in all the samples, at $2 \theta$ of $31.36^{\circ}$ grows with the $\mathrm{Nd}$ content and is readily well visible in the sample $100 \mathrm{Nd} . S O D$.

\subsubsection{SAP based samples}

Starting from the results already reported in literature by the same authors, reactions between SAP powder and metal chlorides $(\mathrm{LiCl}$ and $\mathrm{KCl})$ take place only at temperatures higher than $800{ }^{\circ} \mathrm{C}$ [29]. From XRD, Raman and FTIR spectra, at lower temperatures unreacted salts were found, while the reaction products at increasing temperatures can be attributed to metalaluminosilicate, metal-aluminophosphate and metal phosphate. As expected, the molten $\mathrm{LiCl}-\mathrm{KCl}$ attacks the unstable P-rich region to break the linkage "Si-O-Al-O-P-O-P", thus generating a series of reactive sites, such as $\mathrm{Si-O}-\mathrm{Al}, \mathrm{Al}-\mathrm{O}-\mathrm{P}, \mathrm{P}-\mathrm{O}-\mathrm{P}$ [29].

In the present work heating time, as well as salt/SAP ratio, have been considered. Different LiKCl.SAP samples were prepared by heating at $850{ }^{\circ} \mathrm{C}$ for 5,10 and $20 \mathrm{~h}$ : the products showed an increasing crystallinity by increasing the duration of the thermal

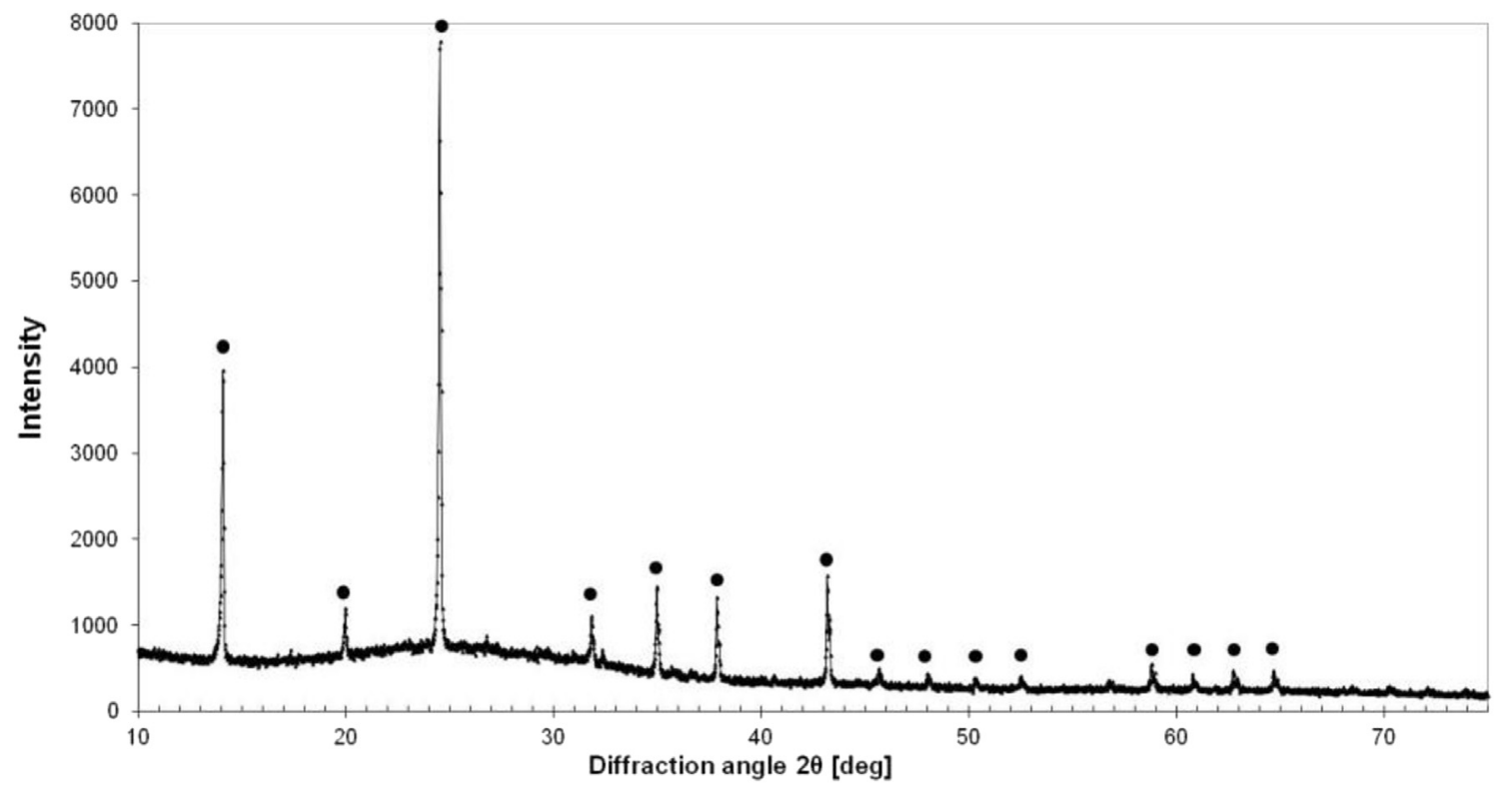

Fig. 1. XRD spectrum of CSW.SOD.GF sample containing the mixed chloride salts and glass frit and treated at $925^{\circ} \mathrm{C}$ for $7 \mathrm{~h}$; black dots indicate sodalite phase. 


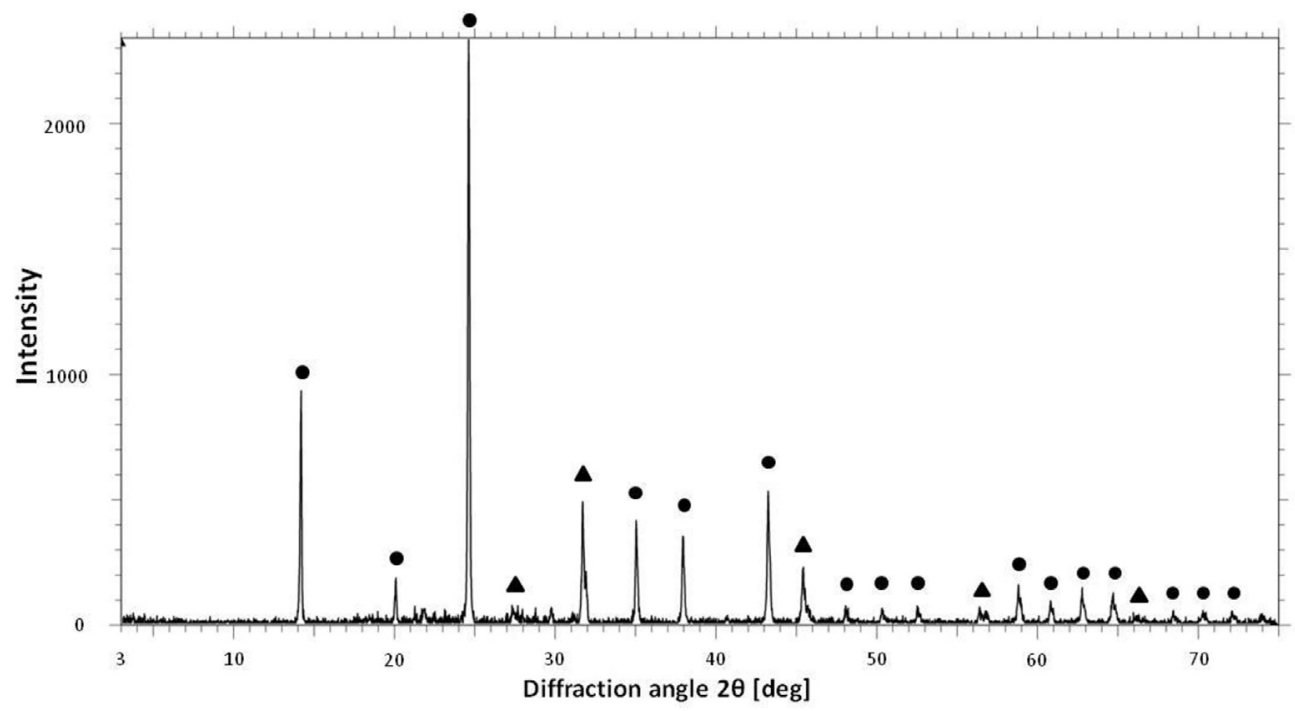

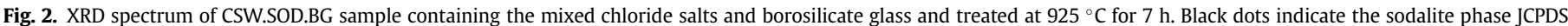
card 79-0091; black triangles indicate the halite phase JCPDS card 5-628.

treatment. Furthermore, samples with salt/SAP ratios of $1: 2,1: 3$ and 1:4 were prepared and reacted at $850{ }^{\circ} \mathrm{C}$. The relative XRD analyses show that an increase in the SAP content results in an increase of free silica. According to the experimental observations performed on the samples obtained at different temperatures, the optimal temperature to guarantee reaction between the reagents was set at $950{ }^{\circ} \mathrm{C}$. In the light of the effects of salt/SAP ratio and thermal treatment duration on the product composition, such parameters were optimized at $950{ }^{\circ} \mathrm{C}$. In particular, LiKCl.SAP samples prepared at $950{ }^{\circ} \mathrm{C}$ with a salt/SAP ratio of $1: 2$ and at different reaction times were synthesized and analyzed by XRD. After a reaction time of $5 \mathrm{~h}, \mathrm{XRD}$ analysis highlights the presence of $\mathrm{SiO}_{2}$ (JCPDS card 46-1045) as the main phase. By increasing the duration of the thermal treatment at $950^{\circ} \mathrm{C}$ up to 10 and $30 \mathrm{~h}$, the residual $\mathrm{SiO}_{2}$ was no more present and the main reflections are consistent with a phase similar to aluminum phosphate (JCPDS card 48-0652) with a slight shift, potassium aluminum phosphate $\left(\mathrm{AlK}\left(\mathrm{P}_{2} \mathrm{O}_{7}\right)\right.$, JCPDS card 34-1370) and lithium phosphate $\left(\mathrm{Li}_{3} \mathrm{PO}_{4}\right.$, JCPDS card 15-0760). Since $30 \mathrm{~h}$ resulted to be the optimal reaction time, new LiKCl.SAP samples were prepared through a thermal treatment at $950{ }^{\circ} \mathrm{C}$ for $30 \mathrm{~h}$ at different salt/SAP ratios. With respect to the 1:2 sample, potassium aluminum pyrophosphate $\left(\mathrm{AlK}\left(\mathrm{P}_{2} \mathrm{O}_{7}\right)\right.$, JCPDS card 34$1370)$ disappeared by increasing the SAP content in the matrices, while some modifications of the XRD patterns in the region $19^{\circ}<2 \theta<25^{\circ}$ seem to suggest the formation of different mixed phosphates.

According to all the above considerations, the optimal conditions for the synthesis of SAP based matrices for the immobilization of chloride waste have been identified as a thermal treatment at $950{ }^{\circ} \mathrm{C}$ for $30 \mathrm{~h}$ with a salt/SAP ratio of $1: 2$. Fig. 3 reports the XRD pattern of CSW.SAP in comparison with LiKCl.SAP prepared under these optimal experimental conditions.

The XRD analyses suggest that the reaction products of SAP with metal chlorides are metal-aluminosilicate, metal-aluminophosphate and metal phosphate, according to the following equations:

$\mathrm{LiCl}+\mathrm{KCl}+\mathrm{CsCl}+\mathrm{SAP} \rightarrow \mathrm{Li}_{3} \mathrm{PO}_{4}+\mathrm{K}_{3} \mathrm{PO}_{4}+\mathrm{Cs}_{2} \mathrm{AlP}_{3} \mathrm{O}_{10}+(\mathrm{Li}, \mathrm{K}$,

Cs)-aluminosilicate $+3 / 2 \mathrm{Cl}_{2}$

$$
\begin{aligned}
& \mathrm{LiCl}+\mathrm{KCl}+\mathrm{SrCl}_{2}+\mathrm{SAP} \rightarrow \mathrm{Li}_{3} \mathrm{PO}_{4}+\mathrm{K}_{3} \mathrm{PO}_{4}+\mathrm{Li}_{\mathrm{x}} \mathrm{K}_{\mathrm{x}} \mathrm{Al}_{\mathrm{x}} \mathrm{Si}_{1-\mathrm{x}} \mathrm{O}_{2-} \\
& \mathrm{x}+\mathrm{Sr}_{5}\left(\mathrm{PO}_{4}\right)_{3} \mathrm{Cl}+2 \mathrm{Cl}_{2} \\
& \mathrm{LiCl}+\mathrm{KCl}+\mathrm{CeCl}_{3}+\mathrm{SAP} \rightarrow \mathrm{Li}_{3} \mathrm{PO}_{4}+\mathrm{K}_{3} \mathrm{PO}_{4}+\mathrm{Li}_{\mathrm{x}} \mathrm{K}_{\mathrm{x}} \mathrm{Al}_{\mathrm{X}} \mathrm{Si}_{1-\mathrm{x}} \mathrm{O}_{2-} \\
& \mathrm{x}+\mathrm{CePO}_{4}+5 / 2 \mathrm{Cl}_{2}
\end{aligned}
$$

In the SAP, there are three kinds of chains, $\mathrm{Si}-\mathrm{O}-\mathrm{Si}$ as a main chain, Si-O-Al as a side chain and Al-O-P/P-O-P as a reactive chain. Alkali metal chlorides were converted into metal aluminosilicates $\left(\mathrm{Li}_{\mathrm{x}} \mathrm{Al}_{\mathrm{x}} \mathrm{Si}_{1-\mathrm{x}} \mathrm{O}_{2-\mathrm{x}}\right)$ and metal phosphates $\left(\mathrm{Li}_{3} \mathrm{PO}_{4}\right.$ and $\left.\mathrm{Cs}_{2} \mathrm{AlP}_{3} \mathrm{O}_{10}\right)$, while alkali earth and rare earth chlorides were changed into only metal phosphates $\left(\mathrm{Sr}_{5}\left(\mathrm{PO}_{4}\right)_{3} \mathrm{Cl}\right.$ and $\left.\mathrm{CePO}_{4}\right)$. These reaction products were compatible with borosilicate glasses which functioned as a chemical binder for metal aluminosilicates and a physical binder for metal phosphates. All these mechanisms strongly affect the leaching behaviors of the elements of the matrix as well as of the chloride waste that would be confined.

The observed phases could be probably attributable to mixed phosphate but no correspondence with those reported in the spectral library was found. In order to get new insights and better understanding of the observed phases in the CSW.SAP samples, a new series of samples was prepared from SAP powder and the chloride salts of $\mathrm{Rb}, \mathrm{Cs}, \mathrm{Sr}, \mathrm{Ba}, \mathrm{La}, \mathrm{Ce}$ and $\mathrm{Nd}$, according to the optimized synthetic route. The final products were characterized by XRD analyses. For the monovalent cations Rb and Cs, XRD investigations on the Rb.SAP and Cs.SAP samples highlighted the presence of hydrogen phosphates of the cations $\left(\mathrm{RbH}_{2} \mathrm{PO}_{4}\right.$, JCPDS card 34-0074 and $\mathrm{CsH}_{2} \mathrm{PO}_{4}$, JCPDS card 35-0746) besides aluminum phosphate (JCPDS card 11-0500). Moreover, in the Rb.SAP sample potassium aluminum silicate hydrate, silica and rubidium oxide were also observed.

Concerning the divalent cations $\mathrm{Sr}$ and $\mathrm{Ba}$, both final samples contain two different phases of aluminum phosphate (JCPDS card 48-0652 and 11-0500). Moreover, the thermal treatment at $850{ }^{\circ} \mathrm{C}$ in the Sr.SAP sample led to the formation of strontium chloride phosphate hydroxide $\left(\mathrm{Sr}_{5} \mathrm{Cl}_{0.65}(\mathrm{OH})_{0.35}\left(\mathrm{PO}_{4}\right)_{3}\right.$, JCPDS card 24-0729), that disappears by increasing the temperature to $950{ }^{\circ} \mathrm{C}$, while strontium phosphate hydrate $\left(\mathrm{H}_{3} \mathrm{Sr}_{6}\left(\mathrm{PO}_{4}\right)_{5}\right.$, JCPDS card 19-1287) has been observed only at the highest temperature. In the Ba.SAP sample barium pyrophosphate $\left(\mathrm{Ba}_{2} \mathrm{P}_{2} \mathrm{O}_{7}\right.$, JCPDS card $\left.30-0144\right)$ has been observed. 


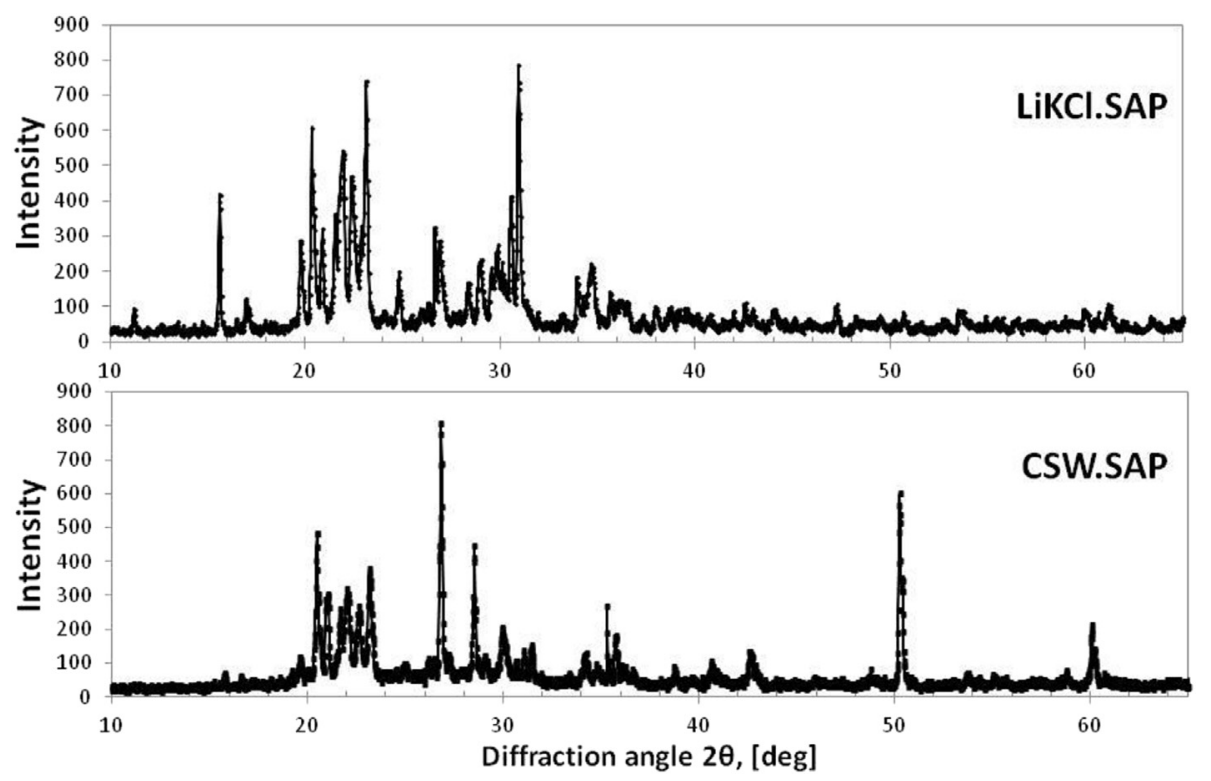

Fig. 3. XRD patterns of LiKCl.SAP (top) and CSW.SAP (bottom) after a thermal treatment at $950{ }^{\circ} \mathrm{C}$ for $30 \mathrm{~h}$.

Concerning the trivalent lanthanide cations, XRD spectra clearly showed the formation of lanthanide phosphate besides aluminum phosphate. In particular, in the case of La.SAP sample, lanthanum phosphate ( $\mathrm{LaPO}_{4}$, JCPDS card 46-1326 and 32-0493) was clearly formed. XRD analyses of Ce.SAP sample revealed the presence of cerium phosphate $\left(\mathrm{CePO}_{4}\right.$, JPCDS card 32-0199) and a phase similar to cerium oxide $\left(\mathrm{CeO}_{2}\right.$, JCPDS card 43-1002) that shows a shift, according to which it could be attributed to a mixed cerium oxide. Moreover, potassium aluminum silicate $\left(\mathrm{KAlSiO}_{4}\right.$, JPCDS card 481028 ) is present. The sample containing Nd shows the formation of neodymium phosphate $\left(\mathrm{NdPO}_{4}\right.$, JCPDS card 46-1328) and a second phase identified as $\mathrm{NdPO}_{4}$ with $\mathrm{Nd}_{2} \mathrm{O}_{3} \cdot \mathrm{P}_{2} \mathrm{O}_{5}$ (JPCDS card 25-1065). In particular, increasing the temperature aluminum phosphate disappears and neodymium phosphate becomes dominant.

Finally, the XRD patterns of the glass-blended SAP samples were essentially amorphous with few peaks not attributable to the glass or chlorides salts. The consolidation mechanism is based on the formation of three kinds of chemical forms in the gel-products: $\mathrm{Si}$ rich phase, Al-containing intermediate phase, and P-rich phase. The role of the glass as chemical binder before the heat treatment is to dissolve the silicate compounds in the gel products, while most of the phosphates are encapsulated by the glassy phase and only a fraction of the P-rich phase is dissolved into the latter. After the thermal treatment cesium, which was preferentially present as silicate phase, is vitrified into a glassy phase. On the other side $\mathrm{Sr}$, which is mainly in the form of phosphate compounds, was encapsulated by the glassy phase. The described mechanisms work together to produce a monolithic wasteform.

For sake of brevity the XRD spectra of the samples described in the present section are reported in the Supplementary Information (Figures SI1-16).

\subsection{Leaching results}

In order to evaluate the feasibility of SOD and SAP to be used as confining matrices for chloride salt wastes and further to compare each other with respect to their retention capacity, leaching tests were performed on CSW.SOD and CSW.SAP blended with glass frit and borosilicate glass.
Leaching tests were performed for up to six contact times (1-715-30-90-150 days) at room temperature $\left(23 \pm 2{ }^{\circ} \mathrm{C}\right)$ and at $90 \pm 2{ }^{\circ} \mathrm{C}$ in an oven. During the leaching tests the $\mathrm{pH}$ was not buffered, but the initial $\mathrm{pH}$ values, as well as the $\mathrm{pH}$ values after each interval of time, were measured. The concentrations of $\mathrm{Li}, \mathrm{Na}$, $\mathrm{Al}, \mathrm{Si}, \mathrm{K}, \mathrm{Rb}, \mathrm{Sr}, \mathrm{Cs}, \mathrm{Ba}$, La and $\mathrm{Nd}$ in the leachate were measured at each time interval.

\subsubsection{CSW.SOD.GF}

In order to better understand the leaching behavior of the final wasteform, tests were also performed on pure SOD samples to evaluate the release of the matrix elements ( $\mathrm{Li}, \mathrm{Na}, \mathrm{Al}, \mathrm{Si}, \mathrm{K}$ ) over time. The normalized releases of the elements of interest in the leachate of the tests performed at $23 \pm 2{ }^{\circ} \mathrm{C}$ roughly seem to reach a constant value in approximately 20 days, except for $\mathrm{Li}$ whose concentration keeps growing from 20 to 150 days (Fig. 4). This relatively high Li release may be attributed to the fact that lithium ions are too small to fit into the Na sites.

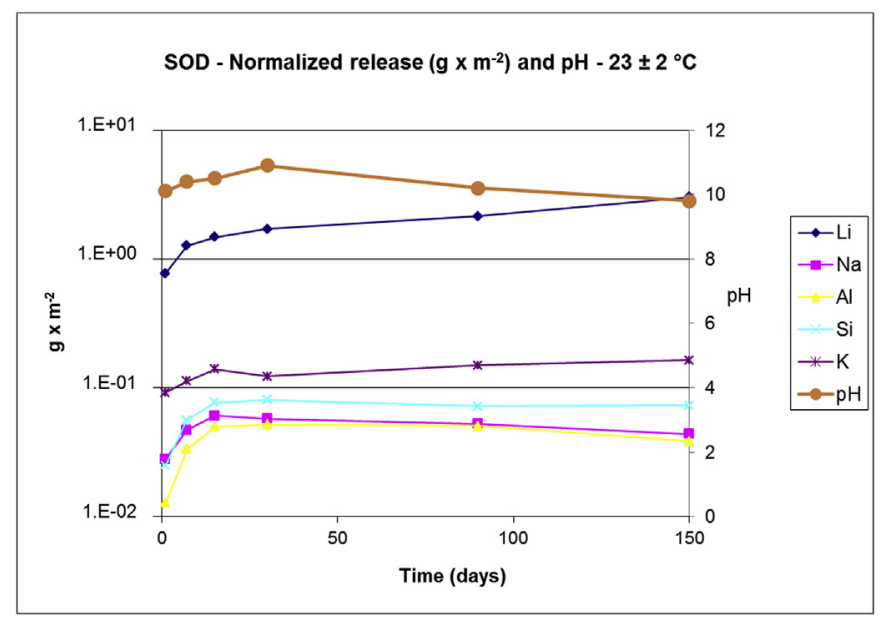

Fig. 4. SOD. Time evolution of the normalized release $\left(\mathrm{g} / \mathrm{m}^{2}\right)$ of the matrix elements at $23 \pm 2{ }^{\circ} \mathrm{C}$ and $\mathrm{pH}$ behavior over time. 
In more detail, $\mathrm{Na}, \mathrm{Al}$ and $\mathrm{Si}$ normalized releases seem to slightly decrease after 30 days while $\mathrm{K}$ normalized release slightly increases. This behavior could be consistent with the precipitation of nepheline secondary phases at the surface, as observed with ( $\mathrm{Na}$, Al) rich-glasses at basic $\mathrm{pH}(\mathrm{pH}>10-10.5)$, and with the dissolution of Li-K chlorides.

As for the leaching tests at $90 \pm 2{ }^{\circ} \mathrm{C}$, the normalized releases of all the matrix elements are roughly constant over time except for the first weeks (Fig. 5).

Actually a plateau is reached even before 20 days for most elements. In more detail Li release grows during the first 30 days and then remains constant. Si release grows between 20 and 90 days and then slightly decreases, the behaviors of $\mathrm{Na}$ and $\mathrm{Al}$ rather than become constant seem to slightly decrease. Again this behavior may be consistent with the precipitation of secondary phases at the surface.

Concerning the CSW.SOD.GF samples, as shown in Fig. 8, the normalized releases of some matrix elements, i.e. Li, Na and K, of tests at $23 \pm 2{ }^{\circ} \mathrm{C}$ are roughly constant over time, whereas $\mathrm{Al}$ and $\mathrm{Si}$ normalized releases increase in the first 30 days and then remain almost constant. Among the fission elements present in the chloride salt (i.e. $\mathrm{Rb}, \mathrm{Sr}, \mathrm{Cs}, \mathrm{Ba}, \mathrm{La}, \mathrm{Nd}$ ) notable releases of $\mathrm{Rb}$ and $\mathrm{Cs}$ have been observed in solution immediately from the beginning of leaching tests performed by the present authors [23,25,29]. The leaching tests at $90 \pm 2{ }^{\circ} \mathrm{C}$ show a similar behavior with some differences (Fig. 8): normalized releases in solution are constant for most elements, except for Li whose release increases in the first 30 days and then remains constant. Also in this case notable releases of $\mathrm{Rb}$ and $\mathrm{Cs}$ have been observed in solution immediately from the beginning of the leaching tests. Moreover a correlation between $\mathrm{La}$ and $\mathrm{Nd}$ and between $\mathrm{Sr}$ and Ba releases is observed.

The behavior over time of the normalized release rates of $\mathrm{Li}, \mathrm{Na}$, $\mathrm{Al}, \mathrm{Si}, \mathrm{K}, \mathrm{Rb}, \mathrm{Sr}, \mathrm{Cs}, \mathrm{Ba}, \mathrm{La}$ and $\mathrm{Nd}$ at $90 \pm 2{ }^{\circ} \mathrm{C}$ are reported in Fig. 9. Higher normalized release rates are observed for $\mathrm{Li}$, Na and $\mathrm{K}$, among the matrix elements, as already observed for pure SOD (see Fig. 6) and for $\mathrm{Rb}$ and $\mathrm{Cs}$, among the fission products. While $\mathrm{Sr}, \mathrm{Ba}$, La and Nd show lower normalized release rates. It is clear that the addition of glass reduces the normalized release rates by almost one order of magnitude.

In order to highlight the effect of the temperature upon release, in Fig. 10 (Table SI3) the percentage releases at $23 \pm 2{ }^{\circ} \mathrm{C}$, after 90 days, are compared with the corresponding percentage releases at $90 \pm 2{ }^{\circ} \mathrm{C}$ for each element under study. Fig. 10 shows that release

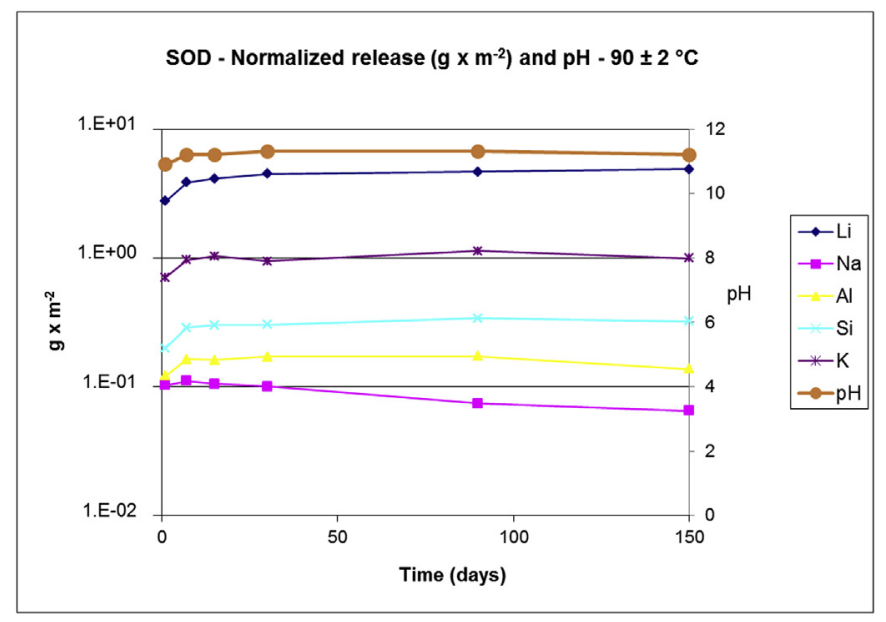

Fig. 5. SOD. Time evolution of the normalized release $\left(\mathrm{g} / \mathrm{m}^{2}\right)$ of the matrix elements at $90 \pm 2{ }^{\circ} \mathrm{C}$ and $\mathrm{pH}$ behavior over time.

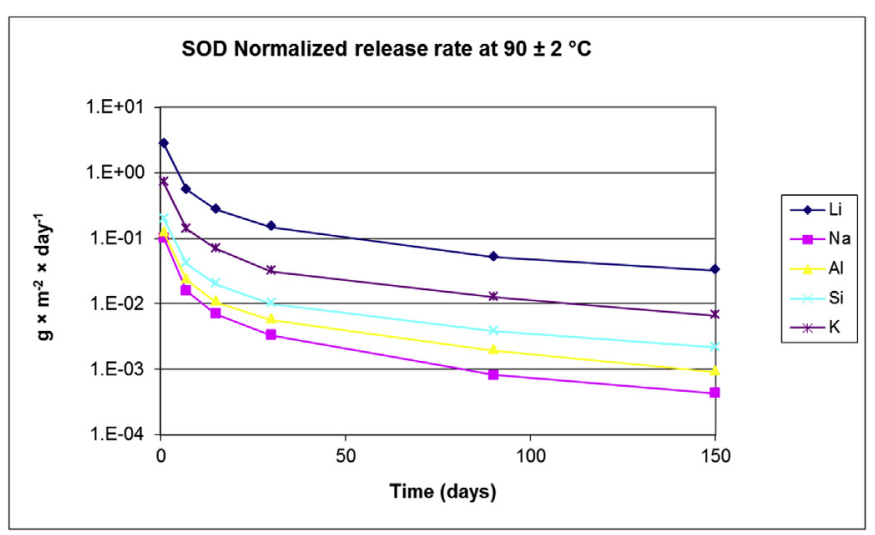

Fig. 6. SOD. Time evolution of the normalized release rates $\left(g \cdot \mathrm{m}^{-2} \cdot \mathrm{day}^{-1}\right)$ at $90 \pm 2{ }^{\circ} \mathrm{C}$.

seems much affected by higher temperature. Leaching tests on pure SOD clearly showed that at $90 \pm 2{ }^{\circ} \mathrm{C}$ the releases of some matrix elements were significant, such as $\mathrm{Li}(\cong 12 \%)$ and $\mathrm{K}(\cong 3 \%)$ while the release of $\mathrm{Na}, \mathrm{Al}$ and $\mathrm{Si}$ were less than $1 \%$ (Fig. 7 and Table SI2). For the CSW.SOD.GF sample, in spite of non-negligible releases of some matrix elements ( $\cong 3 \%$ ), especially if compared with results obtained with SOD, the release of all fission products were less than the $1.5 \%$.

Concerning $\mathrm{pH}$ changes in the case of pure SOD, during the leaching tests at $23 \pm 2{ }^{\circ} \mathrm{C} \mathrm{pH}$ increased immediately (after $1 \mathrm{~h}$ ) to 10 and reached 11 after 30 days and then it decreased to 10 again after 150 days. During the leaching tests at $90 \pm 2{ }^{\circ} \mathrm{C}$ the $\mathrm{pH}$ increased to 11 after 1 day and then it remained almost constant until the end of the leaching test (Fig. 4). In the case of CSW.SOD.GF, the $\mathrm{pH}$ measured after $1 \mathrm{~h}$ from the beginning of the leaching test was still almost neutral $(\mathrm{pH}=7.2)$. During the leaching tests at $23 \pm 2{ }^{\circ} \mathrm{C}$ the $\mathrm{pH}$ slightly grew up to 8.2 after 30 days and then decreased to 7.6 after 150 days, whereas during the tests at $90 \pm 2{ }^{\circ} \mathrm{C}$ it grew up to 10 after 1 day and then remained almost constant.

SEM investigations carried out on the sodalite powder before and after leaching tests (Fig. 11) clearly showed the effect of the leaching process at $90{ }^{\circ} \mathrm{C}$ : after 30 days a partial dissolution of the surface layer of the sodalite grain can be discerned (Fig. 11c); later on, after 150 days, lots of small holes appear in accordance with the notable observed releases (Fig. 11d). Whereas there is no evidence of a comparable degradation effect on the surface of a sodalite grain leached at $23{ }^{\circ} \mathrm{C}$ for 150 days (Fig. 11b).

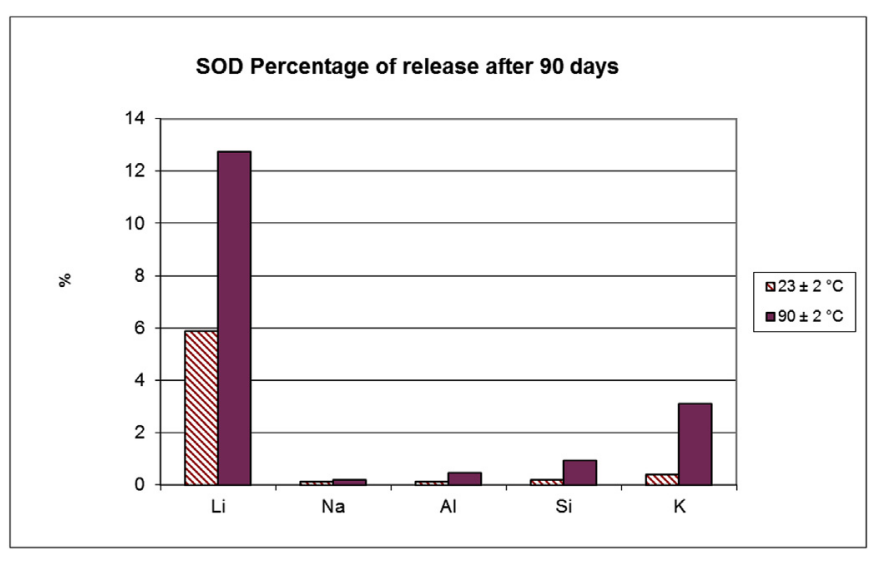

Fig. 7. SOD. Percentage of release after 90 days at $23 \pm 2{ }^{\circ} \mathrm{C}$ and at $90 \pm 2{ }^{\circ} \mathrm{C}$. 

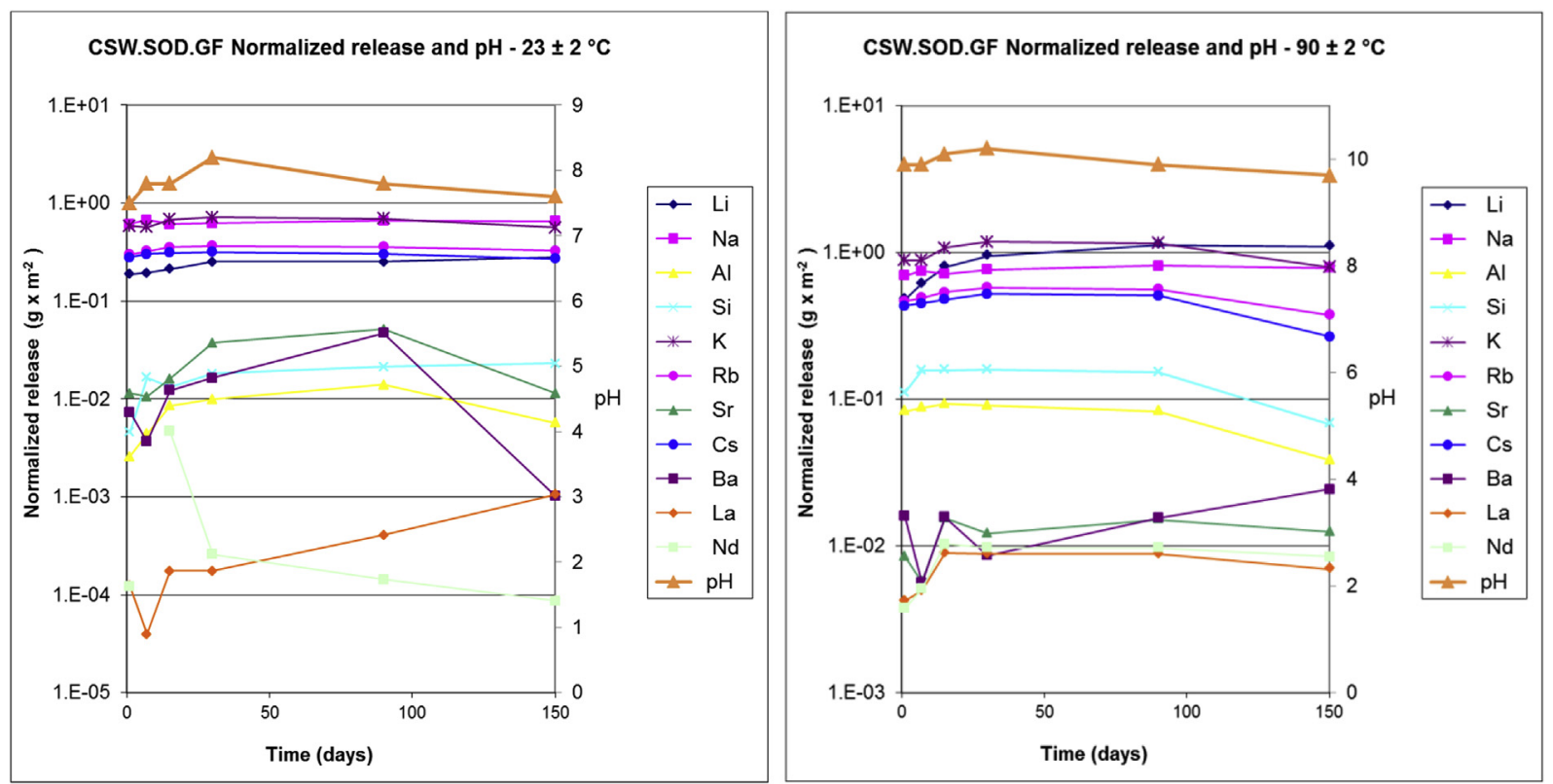

Fig. 8. CSW.SOD.GF. Time evolution of $\mathrm{pH}$ and normalized releases $\left(\mathrm{g} / \mathrm{m}^{2}\right)$ at $23 \pm 2{ }^{\circ} \mathrm{C}$ (left) and at $90 \pm 2{ }^{\circ} \mathrm{C}$ (right) $[23,24]$.

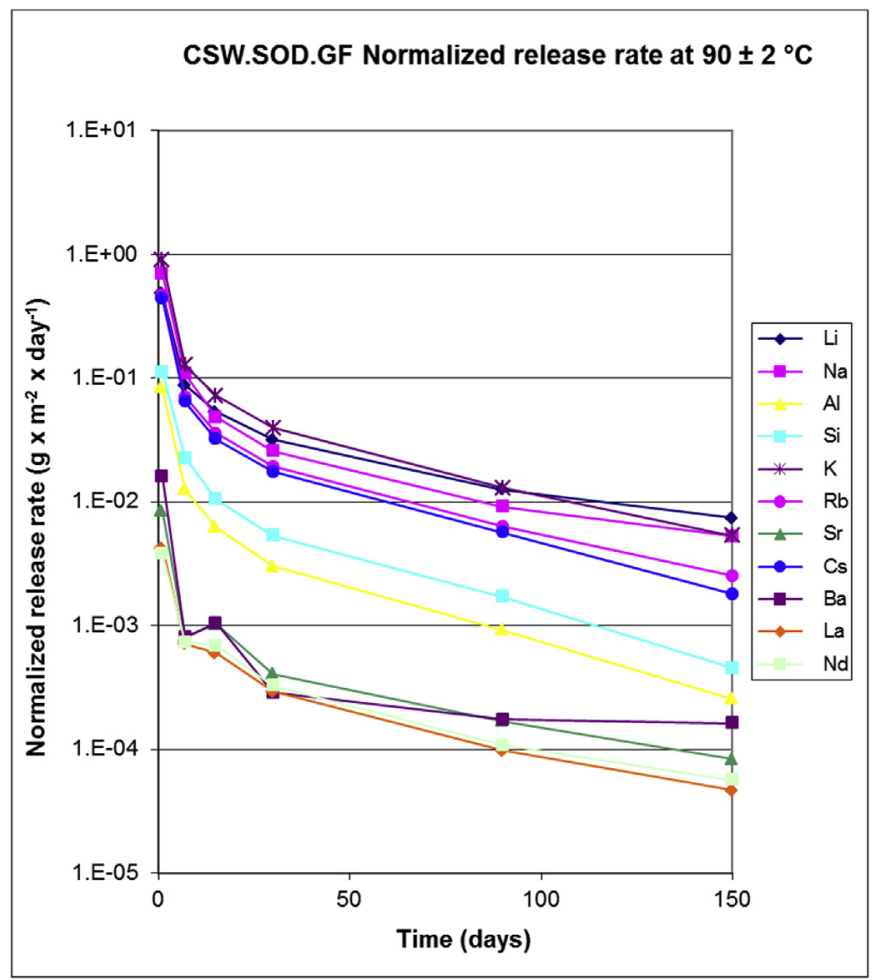

Fig. 9. CSW.SOD.GF. Time evolution of the normalized release rates $\left(\mathrm{g} \cdot \mathrm{m}^{-2} \cdot \mathrm{day}^{-1}\right)$ at $90 \pm 2{ }^{\circ} \mathrm{C}[23]$.

Analogous SEM investigations on CSW.SOD.GF samples (Fig. 12) showed that after 30 days at $90 \pm 2{ }^{\circ} \mathrm{C}$ (Fig. 12c) a few small holes appear on the surface of the sodalite blended with glass frit but, with respect to the sodalite leached in the same conditions (Fig. 11c), the surface structure is still preserved. The presence of holes becomes even more evident after 90 days and at the highest temperature (Fig. 12d). Note that the small particles on the surface are not due to leaching dissolution but were present soon after the preparation of the sample.

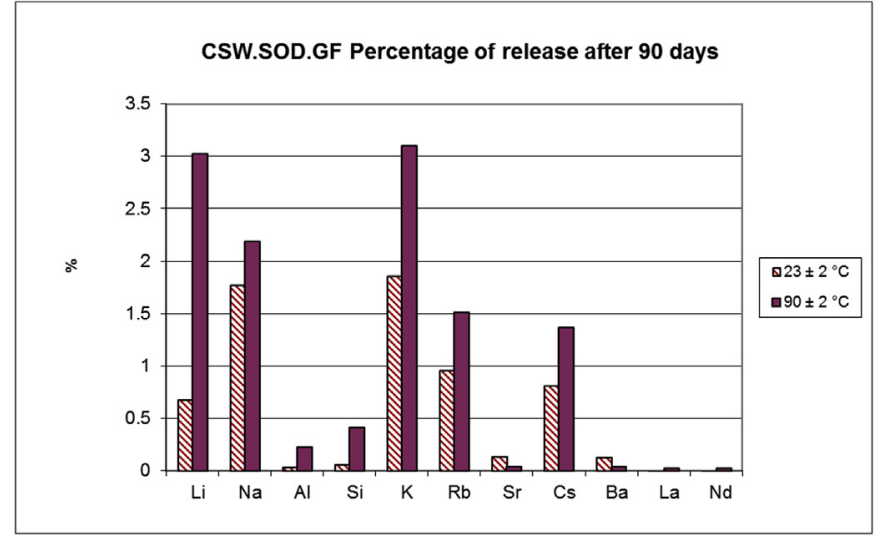

Fig. 10. CSW.SOD.GF. Percentage of release after 90 days at $23 \pm 2^{\circ} \mathrm{C}$ and at $90 \pm 2{ }^{\circ} \mathrm{C}$.

\subsubsection{CSW.SOD.BG}

As shown in Fig. 13, the $\mathrm{pH}$ measured after $1 \mathrm{~h}$ from the beginning of the leaching test on CSW.SOD.BG samples was slightly basic ( $\mathrm{pH}=7.7$ ); at $23 \pm 2{ }^{\circ} \mathrm{C}$ it increased to 8.1 after 7 days and remained almost constant from then on. Whereas during the tests at $90 \pm 2{ }^{\circ} \mathrm{C}$ the $\mathrm{pH}$ increased up to 9.6 after 7 days and then remained almost constant. The normalized releases of $\mathrm{Li}, \mathrm{Na}, \mathrm{K}$ and $\mathrm{Al}$ in the leachate of the tests at $23 \pm 2{ }^{\circ} \mathrm{C}$ are roughly constant over time, whereas Si release increases in the first 15 days and then remains almost constant. Among the fission elements present in the chloride salt wastes ( $\mathrm{Rb}, \mathrm{Sr}, \mathrm{Cs}, \mathrm{Ba}$, La and $\mathrm{Nd}$ ) notable releases of $\mathrm{Rb}$ and $\mathrm{Cs}$ have been observed in solution immediately from the beginning of the leaching tests. Moreover it can be noticed that the behavior over time of the normalized releases of $\mathrm{Ba}$ is similar to $\mathrm{Sr}$ and this also happens for the couples La-Nd and Rb-Cs as would be expected due to similar chemistries and possibly to the same positions inside the matrix.

As for the leaching tests at $90 \pm 2{ }^{\circ} \mathrm{C}$ the behavior is similar: normalized releases are constant for most elements. Also in this case notable releases of $\mathrm{Rb}$ and $\mathrm{Cs}$ have been observed in solution immediately from the beginning of the leaching tests. Moreover the 


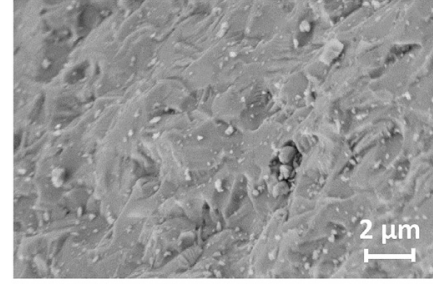

(a)

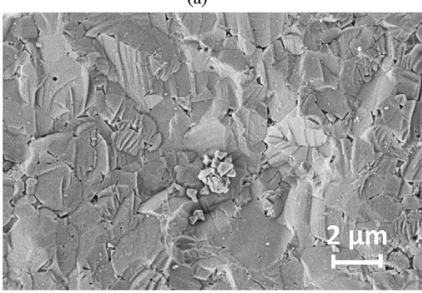

(c)

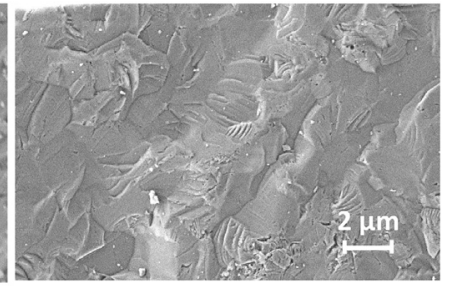

(b)

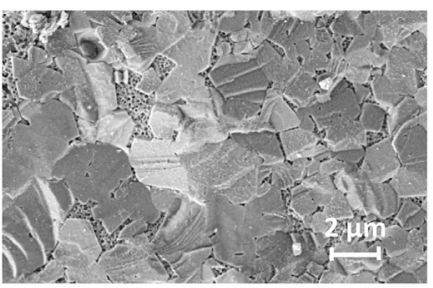

(d)
Fig. 11. SOD. Grain surface (a) before leaching test (Mag.20000x), (b) after 150 days at $23 \pm 2{ }^{\circ} \mathrm{C}$ (Mag.20000x), (c) after 30 days at $90 \pm 2{ }^{\circ} \mathrm{C}$ (Mag.20000x) and (d) after 150 days at $90 \pm 2{ }^{\circ} \mathrm{C}$ (Mag.20000x).

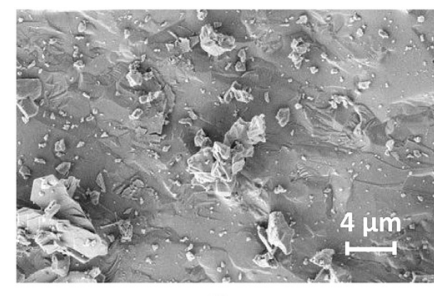

(a)

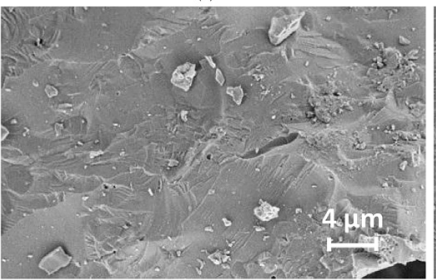

(c)

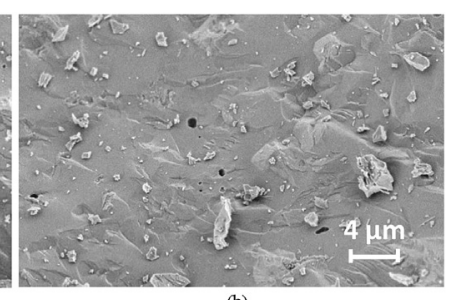

(b)

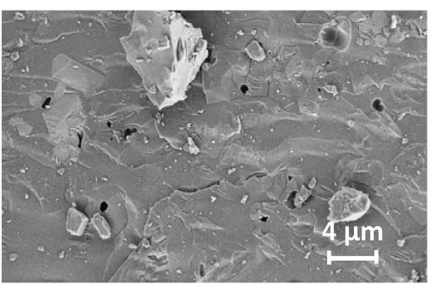

(d)
Fig. 12. CSW.SOD.GF. Grain surface (a) before leaching test (Mag.10000x), (b) after 90 days at $23 \pm 2{ }^{\circ} \mathrm{C}$ (Mag.10000x) (c) after 30 days at $90 \pm 2{ }^{\circ} \mathrm{C}$ (Mag.10000x) and (d) after 90 days at $90 \pm 2{ }^{\circ} \mathrm{C}$ (Mag.10000x).

normalized releases of $\mathrm{La}, \mathrm{Nd}, \mathrm{Ba}$ and $\mathrm{Sr}$ in solution show the same behavior. Note that the values of the element concentrations obtained in the leaching tests at $90 \pm 2{ }^{\circ} \mathrm{C}$ after 90 and 150 days are affected by a leachate evaporative loss which is greater than $5 \%$ (maximum value required by the ASTM C1285-02 [34] procedure) but definitely lower than $10 \%$. Therefore the results referring to 90 and 150 days leaching tests at $90 \pm 2{ }^{\circ} \mathrm{C}$ could be affected by an inaccuracy which is at most $10 \%$. Nevertheless they are still significant for the purpose of the present study and for this reason have been reported here. The normalized release rates of $\mathrm{Li}, \mathrm{Na}, \mathrm{Al}$, $\mathrm{Si}, \mathrm{K}, \mathrm{Rb}, \mathrm{Sr}, \mathrm{Cs}, \mathrm{Ba}, \mathrm{La}, \mathrm{Nd}\left(90 \pm 2{ }^{\circ} \mathrm{C}\right)$ are shown in Fig. 14.

In order to show the effect of the temperature of the leaching tests upon the release, in Fig. 15 (Table SI4) the percentage releases at $23 \pm 2{ }^{\circ} \mathrm{C}$, after 90 days, are compared with the corresponding percentage releases at $90 \pm 2{ }^{\circ} \mathrm{C}$ for each element under study. Fig. 15 shows that only the releases of Li and B are considerably affected by higher temperature, due to their volatility, while the releases of $\mathrm{Na}, \mathrm{K}, \mathrm{Rb}$ and $\mathrm{Cs}$ do not seem much affected by temperature. In spite of non-negligible releases of some matrix elements such as $\mathrm{Li}(\cong 10 \%)$ and $\mathrm{Na}(\cong 5 \%)$, especially if compared with results obtained with pure SOD (Fig. 7), the release of all fission products was less than $1 \%$. The major release observed for both salt elements $\mathrm{Na}$ and $\mathrm{Li}$ can be explained by the presence of halite, as evidenced by XRD spectra (Fig. 2).

SEM investigations were carried out on the CSW.SOD.BG before and after leaching tests. As shown in Fig. 16, it can be observed that after 90 days at $23 \pm 2{ }^{\circ} \mathrm{C}$ and after only 1 day at $90 \pm 2{ }^{\circ} \mathrm{C}$ an increasing and significant quantity of small holes appears on the surface.

\subsubsection{CSW.SAP.GF}

Leaching tests were performed on SAP loaded with chloride salt waste (CSW.SAP) and blended with glass frit (CSW.SAP.GF) for five contact times (1-7-15-30-90 days) in an oven at $90 \pm 2{ }^{\circ} \mathrm{C}$. Concerning CSW.SAP samples, Fig. 17 shows that the releases of some matrix elements were significant after just 7 days at $90 \pm 2{ }^{\circ} \mathrm{C}$, even if compared with the results obtained for sodalite after 90 days reported in Fig. 7. Major releases were observed for $\mathrm{Li}(\cong 20 \%), \mathrm{P}$

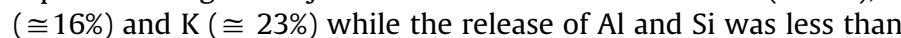
$3 \%$. Moreover significant concentration of $\mathrm{Cs}, \mathrm{Rb}, \mathrm{Sr}$ and $\mathrm{Ba}$ were released in solution. During the 7 days leaching test at $90 \pm 2{ }^{\circ} \mathrm{C}$ the $\mathrm{pH}$ immediately increased to 9 (after $1 \mathrm{~h}$ ) and then decreased to 7 .

In the case of CSW.SAP.GF samples, the pH after $1 \mathrm{~h}$ was 8.1 and it reached the value 8.6 after 90 days (Fig. 18). Concentrations in the leachate of all elements slightly increase over time during leaching tests at $90 \pm 2{ }^{\circ} \mathrm{C}$ up to 90 days. The normalized release of some matrix elements such as $\mathrm{Li}$ and Na was greater than other elements but still lower by one order of magnitude compared to CSW.SOD.GF leaching results reported in paragraph 3.2.1. Also the releases of $\mathrm{Ba}$, $\mathrm{Nd}$ and La were very low compared to the results obtained with CSW.SOD.GF. The normalized releases of all elements increased very slowly over time from 7 to 30 days and become almost constant from 30 to 90 days (Fig. 18).

Fig. 19 shows the behavior over time of the normalized release rates of $\mathrm{Li}, \mathrm{Na}, \mathrm{Al}, \mathrm{Si}, \mathrm{K}, \mathrm{Rb}, \mathrm{Sr}, \mathrm{Cs}, \mathrm{Ba}, \mathrm{La}, \mathrm{Ce}, \mathrm{Pr}, \mathrm{Nd}, \mathrm{P}, \mathrm{Ca}$ and B at $90 \pm$ $2{ }^{\circ} \mathrm{C}$ up to 90 days. Higher normalized release rates are observed for $\mathrm{Li}$, $\mathrm{Na}$ and $\mathrm{K}$, among the matrix elements, and for $\mathrm{Rb}$ and $\mathrm{Cs}$, among the fission products, while $\mathrm{Sr}, \mathrm{Ba}, \mathrm{La}, \mathrm{Ce}, \mathrm{Pr}$ and $\mathrm{Nd}$ show lower normalized release rates.

Fig. 20 compares the percentage releases after 90 days at $90 \pm 2$ ${ }^{\circ} \mathrm{C}$ : matrix element releases were less than $\cong 2 \%$ while the releases of the fission products were below $0.2 \%$, except for $\mathrm{Rb}(\cong 0.4 \%$ ) (Table SI6).

Compared to SAP without the addition of glass frit (CSW.SAP) the percentage of release after 90 days at $90 \pm 2{ }^{\circ} \mathrm{C}$ was many orders of magnitude lower even when compared with releases after 7 days (Fig. 17 and Table SI5). Therefore, the addition of glass frit to SAP significantly reduces the matrix element releases.

SEM investigations were also carried out on CSW.SAP.GF samples before and after the leaching tests. After 7 and 30 days (Fig. 21) some small depressions can be seen but the surface structure is still preserved.

\subsubsection{CSW.SAP.BG}

Several CSW.SAP samples were blended with borosilicate glass and submitted to leaching tests. Results showed that, when the reaction time was increased from $1 \mathrm{~h}$ (CSW.SAP.BG1) to $4 \mathrm{~h}$ (CSW.SAP.BG2), some differences were observed in the ability of the matrix to retain metal cations. Compared to CSW.SAP (Fig. 17 and Table SI5) the borosilicate glass powder addition in CSW.SAP.BG1 does not significantly reduce the releases of matrix elements, while the release of fission products is reduced up to 1 order of magnitude (Fig. 22 and Table SI7). Interestingly, in CSW.SAP.BG2 the borosilicate glass powder addition reduces the matrix element releases up 

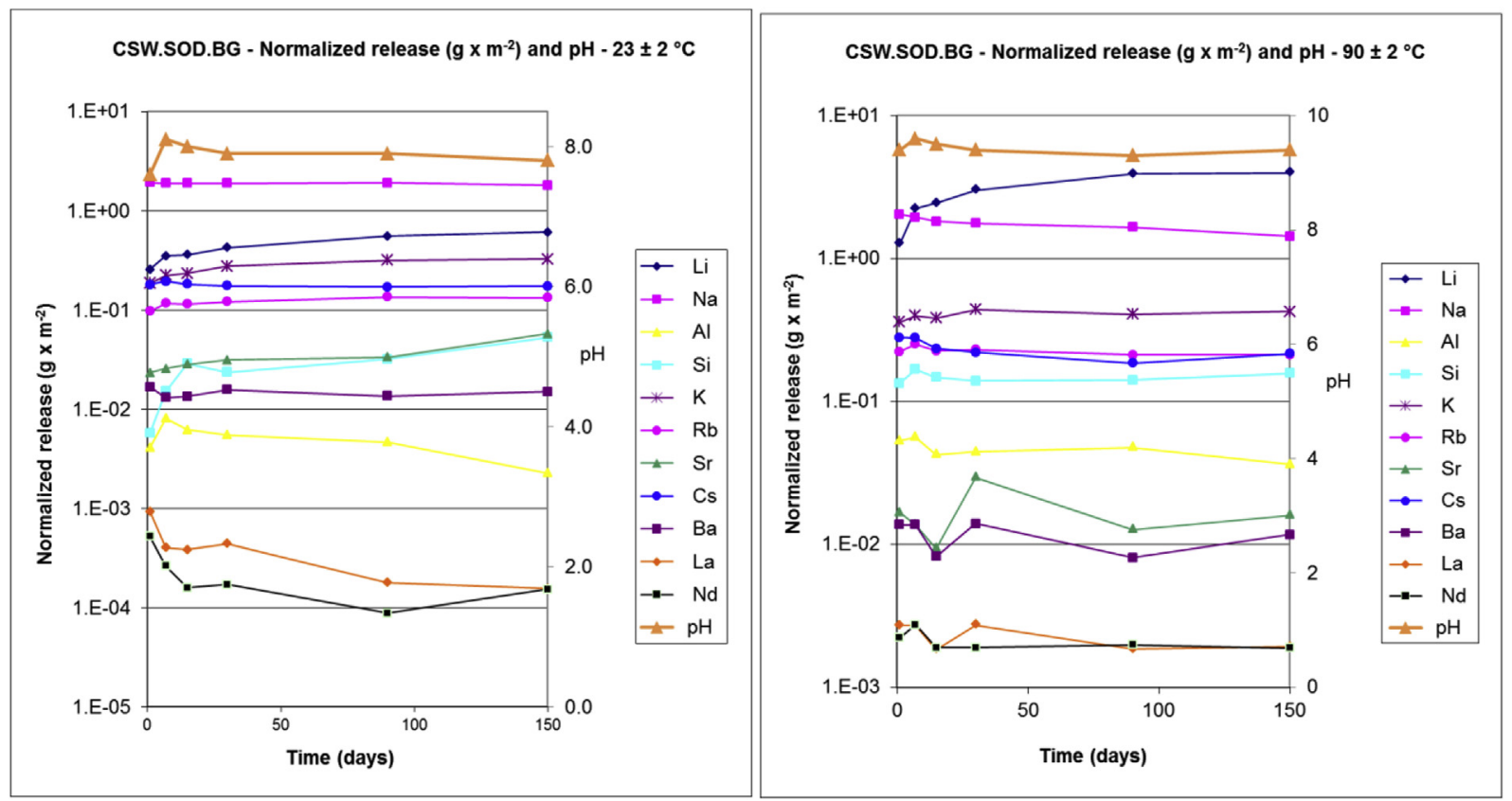

Fig. 13. CSW.SOD.BG. Time evolution of $\mathrm{pH}$ and normalized releases $\left(\mathrm{g} / \mathrm{m}^{2}\right)$ at $23 \pm 2{ }^{\circ} \mathrm{C}$ (left) and $90 \pm 2{ }^{\circ} \mathrm{C}$ (right) [24].

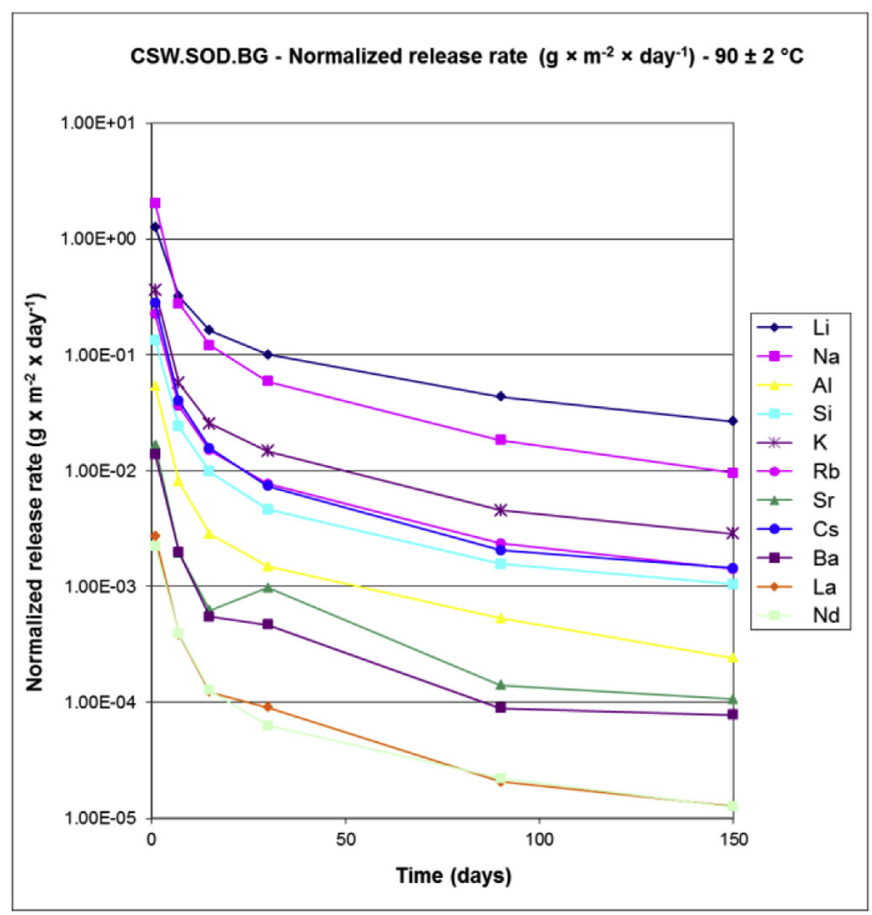

Fig. 14. CSW.SOD.BG. Time evolution of the normalized release rates $\left(\mathrm{g} \cdot \mathrm{m}^{-2} \cdot\right.$ day $\left.^{-1}\right)$ at $90 \pm 2{ }^{\circ} \mathrm{C}$.

to 1 order of magnitude, while the releases of fission products are reduced of 2, 3 or even 4 orders of magnitude (Fig. 23 and Table SI8). Some changes were observed also in $\mathrm{pH}: \mathrm{pH}$ remained constant at the value 7.5 for CSW.SAP.BG1 and around $9\left(23 \pm 2{ }^{\circ} \mathrm{C}\right)$ and $8\left(90 \pm 2^{\circ} \mathrm{C}\right)$ for CSW.SAP.BG 2 .

Fig. 24 compares normalized releases after 7 days at $90{ }^{\circ} \mathrm{C}$ of the SAP and SAP-BG samples. It is clear that the addition of the borosilicate glass greatly improves the retention specifically of the fission products, but not of the matrix elements. The matrix

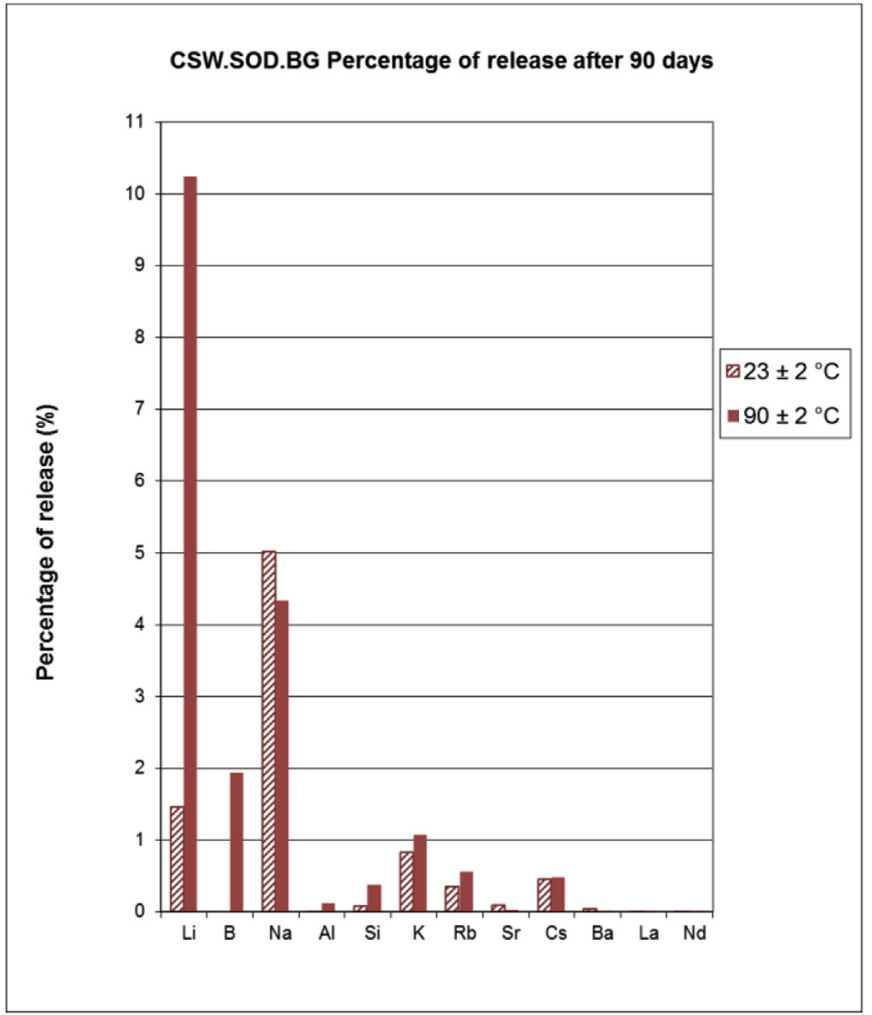

Fig. 15. CSW.SOD.BG leaching tests. Percentage of release after 90 days at $23 \pm 2{ }^{\circ} \mathrm{C}$ and at $90 \pm 2{ }^{\circ} \mathrm{C}$.

CSW.SAP.BG2 made from SAP blended with borosilicate glass and reacted for $4 \mathrm{~h}$ resulted in the better retention of fission products among the SAP-BG studied matrices. Finally, from the profile obtained for LiKCl.SAP.BG it is clear that the release of matrix elements is not affected by the introduction of a mixture of chlorides (CSW) instead of the eutectic melt $\mathrm{LiCl}-\mathrm{KCl}$ (59-41 $\mathrm{mol} \%$ ). 


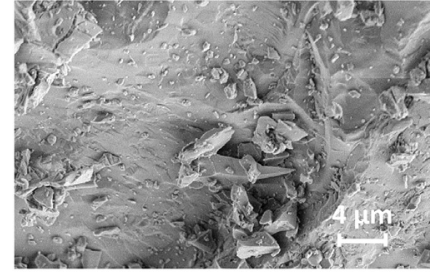

(a)
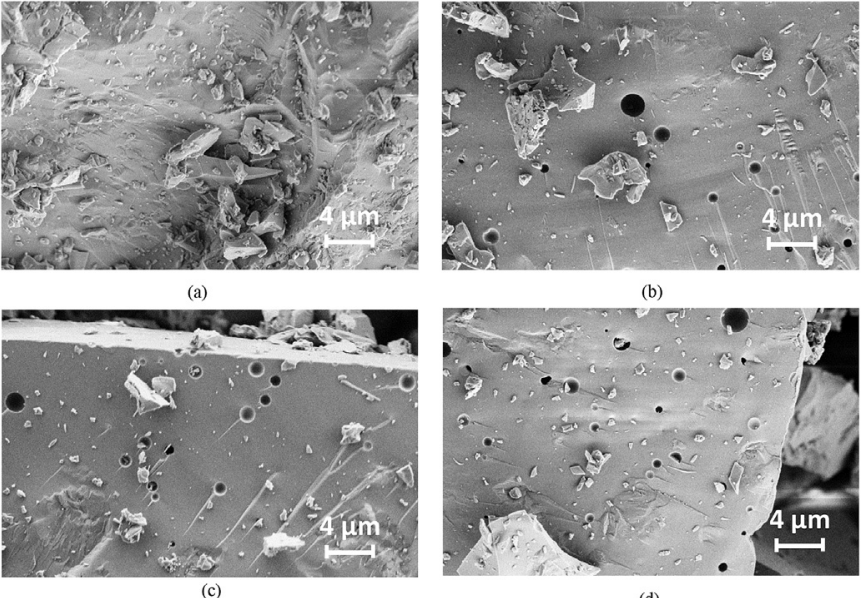

(b)

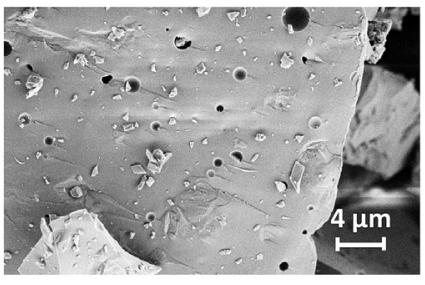

(d)

Fig. 16. Surface of CSW.SOD.BG grains: (a) before leaching tests [24] (Mag. 10000x); (b) after 90 days at $23 \pm 2{ }^{\circ} \mathrm{C}$ (Mag. 10000x); (c) after 1 day at $90 \pm 2{ }^{\circ} \mathrm{C}$ (Mag. 10000x); (d) after 90 days at $90 \pm 2{ }^{\circ} \mathrm{C}$ (Mag. 10000x).

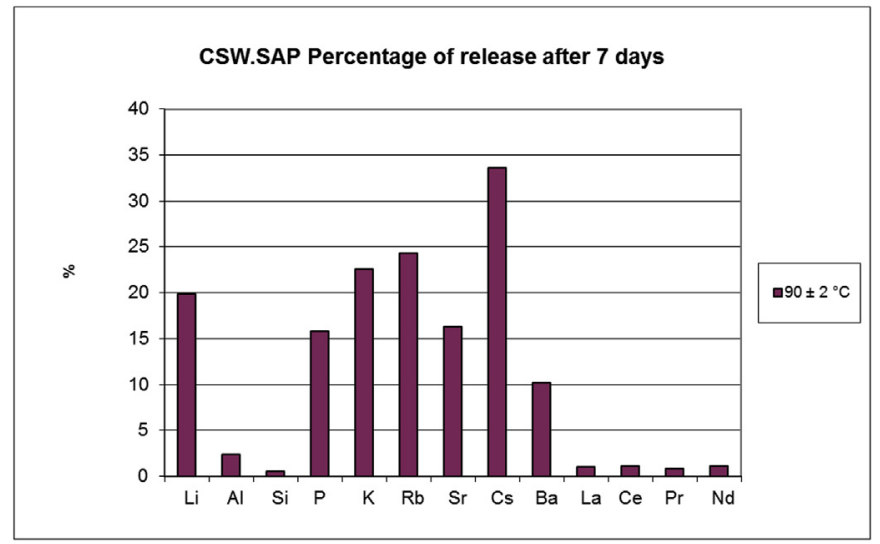

Fig. 17. CSW.SAP leaching tests. Percentage of release after 7 days at $90 \pm 2{ }^{\circ} \mathrm{C}$.

\subsubsection{Final remarks}

Fig. 25 summarizes the results, in terms of normalized release after 7 days at $90^{\circ} \mathrm{C}$, obtained for all the matrices of this study. Even if 7 days is a rather short period to evaluate dissolution behavior, it is worth to make some comments and comparisons regarding 7 days tests, without inferring long term performances.

According to Fig. 25, alkaline ( $\mathrm{Na}, \mathrm{Li}, \mathrm{K}, \mathrm{Rb}, \mathrm{Cs}$ ) and alkaline earth ( $\mathrm{Ca}, \mathrm{Sr}, \mathrm{Ba}$ ) metals are more leachable than lanthanide metals ( $\mathrm{La}$, $\mathrm{Ce}, \mathrm{Pr}, \mathrm{Nd}$ ) as it could be expected due to the fact that alkali metals and alkaline earths are more soluble in aqueous solutions and generally leach more readily from glass and ceramic wasteforms.

It should also be noted that the behavior of salt ions introduced with the mixture of waste is consistent with the following:

- a greater release of monovalent ions of alkali elements (rubidium and cesium), harder to retain and consequently more mobile in the environment;

- an intermediate release for bivalent ions of alkaline earth metals (strontium and barium);

- a minor release for the trivalent ions of lanthanides.

By comparing the normalized releases of CSW.SOD.BG with the corresponding ones of CSW.SOD.GF after 7 days at $90{ }^{\circ} \mathrm{C}$, the two SOD-based samples show comparable releases. On the contrary, by

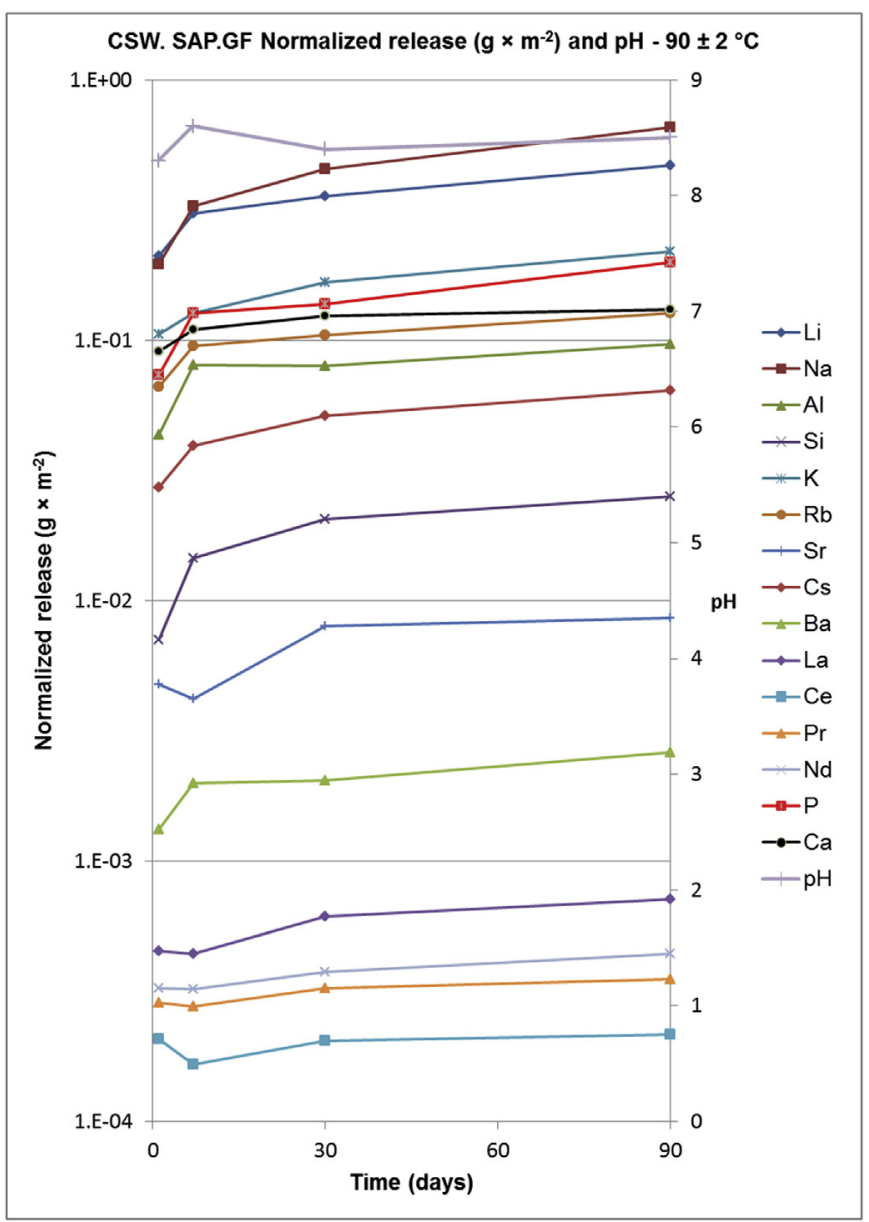

Fig. 18. CSW.SAP.GF. Time evolution of $\mathrm{pH}$ and normalized releases $\left(\mathrm{g} / \mathrm{m}^{2}\right)$ at $90 \pm 2{ }^{\circ} \mathrm{C}$.

comparing CSW.SAP.BG2 with CSW.SAP.GF it is apparent that the addition of GF reduces by one order of magnitude the release of $K, P$, $\mathrm{Na}$ and $\mathrm{Ca}$ among matrix elements and of $\mathrm{Rb}$ and $\mathrm{Cs}$ among fission products. Thus, the immobilization properties of SAP blended with glass frit are better than CSW.SAP.BG2 for most fission products except for Ba and Nd.

Finally, by comparing the leaching behavior of CSW.SAP.GF after 7 days at $90{ }^{\circ} \mathrm{C}$ with that of CSW.SOD matrices blended with glass, it is evident that, for most fission products, CSW.SAP.GF releases are lower by at least one order of magnitude. Thanks to the long term leaching tests here performed for some of the studied matrices it is also possible to affirm that the same behavior is maintained up to 90 days (Fig. 26). Therefore, among the studied matrices, CSW.SAP.GF showed the best confining performances with respect to both matrix elements and fission products.

\section{Discussion}

An attempt was made to collect as much as possible literature data comparable with the results of the present study. For this purpose, Table 3 reports herein obtained data and literature results related to:

- analogous ceramic wasteforms previously studied by the present authors [24,25,30];

- ceramic waste forms containing sodalite with the addition of 25 wt\% glass frit, synthesized at Argonne National Laboratory 


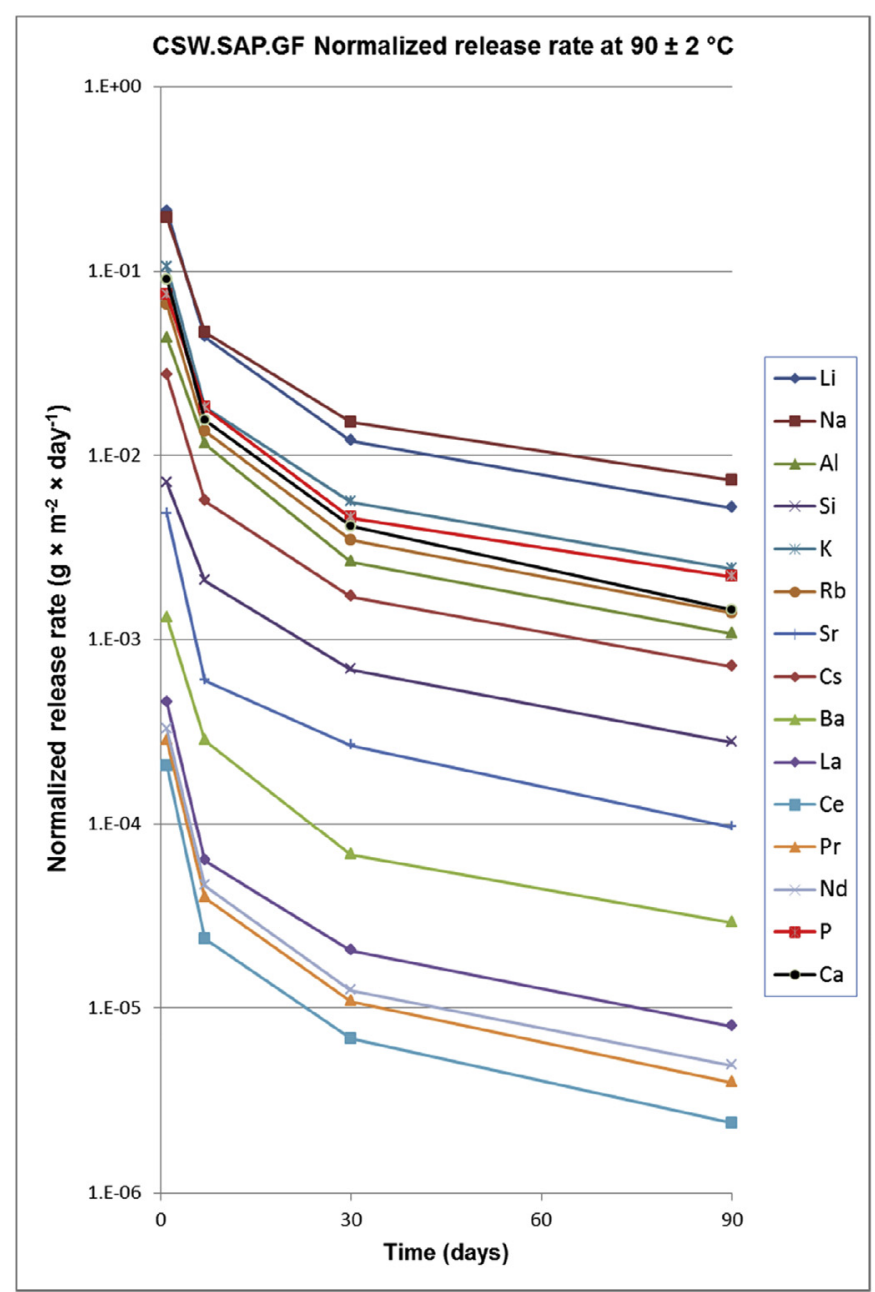

Fig. 19. CSW.SAP.GF leaching tests. Time evolution of the normalized release rates $\left(\mathrm{g} \cdot \mathrm{m}^{-2} \cdot\right.$ day $\left.^{-1}\right)$ at $90 \pm 2{ }^{\circ} \mathrm{C}$.

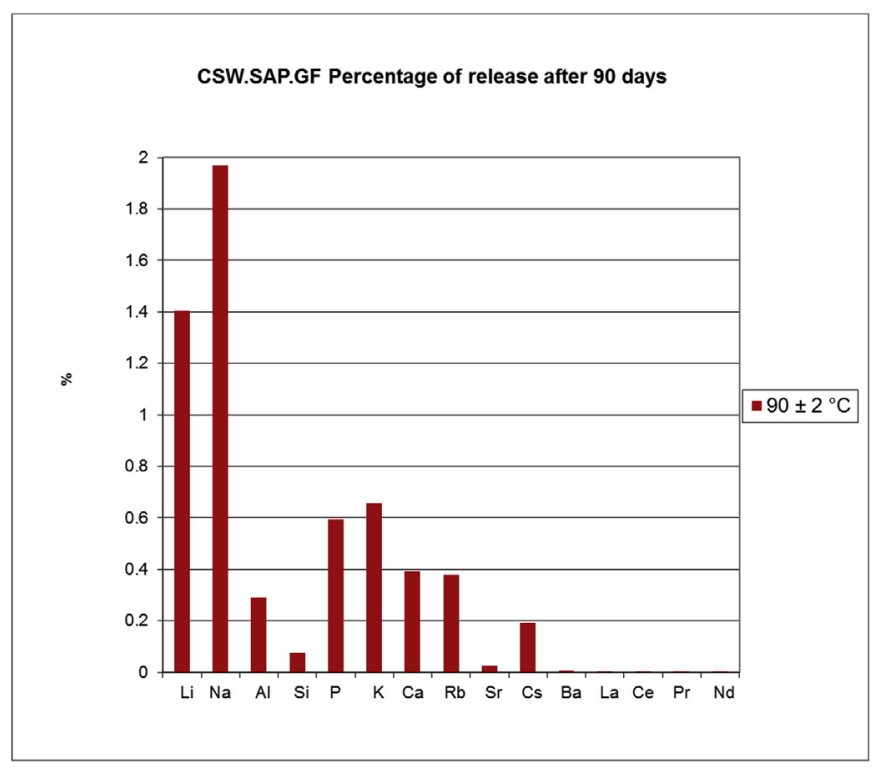

Fig. 20. CSW.SAP.GF leaching tests. Percentage of release after 90 days at $90 \pm 2{ }^{\circ} \mathrm{C}$.

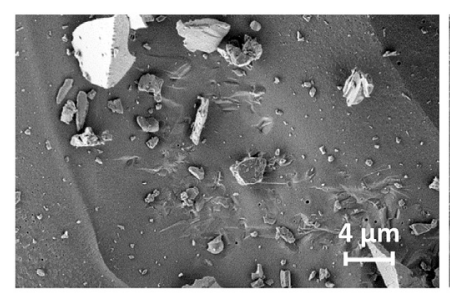

(a)

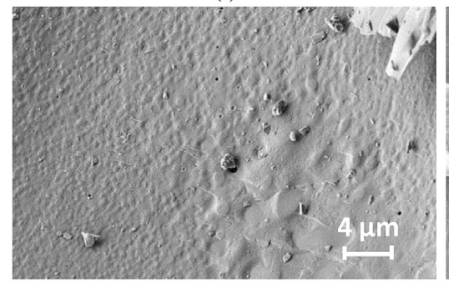

(c)
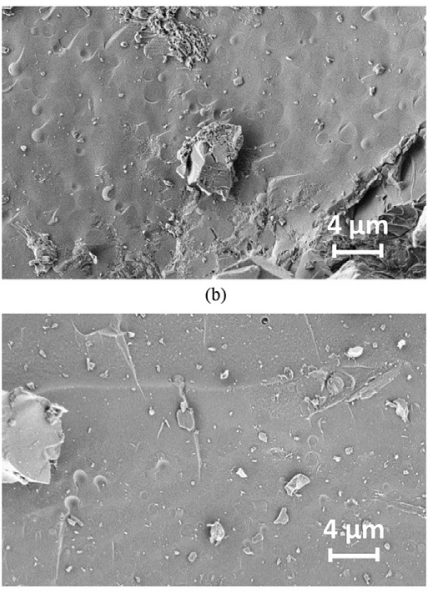

(d)
Fig. 21. CSW.SAP.GF leaching tests. Surface of grains: (a) before leaching tests (Mag.10000x); (b) after 7 days at $90 \pm 2{ }^{\circ} \mathrm{C}$ (Mag.10000x); (c) after 30 days at $90 \pm 2{ }^{\circ} \mathrm{C}$ (Mag.10000x) and (d) after 90 days at $90 \pm 2{ }^{\circ} \mathrm{C}$ (Mag.10000x).

(ANL) through Hot Isostatic Pressing (HIP) and through

Pres-sureless Consolidation (PC) [12]

- a ceramic waste form composed of about $70 \mathrm{wt} \%$ of sodalite, $25 \mathrm{wt} \%$ of binder glass, and a $5 \%$ total of inclusion phases (halite, nepheline and various oxides and silicates) obtained at ANL through Hot Isostatic Pressing (HIP) [11,13];

- a SOD-based matrix with the addition of $25 \mathrm{wt} \%$ of borosilicate glass frit obtained at Idaho National Laboratory (INL) through Pressureless Consolidation (PC) [15]

- a SAP based matrix (50 wt\%) with the addition of CSW (25 wt\%) and of borosilicate glass (25 wt\%), with a ratio SAP/salt $=2$, termed SAP 125, obtained at Korean Atomic Energy Research Institute (KAERI) [27]

The data shown in Table 3 allow a number of considerations to be made. Very few literature works report the behavior of sodaliteand SAP-based matrices and even less data can be found regarding the release of fission product chlorides. Concerning the matrix elements, CSW.SOD.BG shows releases significantly higher with respect to similar matrices reported in the literature, while CSW.SOD.GF shows releases only slightly higher (Table 3). On the contrary, it was observed that cesium, characterized by a high solubility in water, seems to be better retained by both the herein studied sodalite-based matrices compared to literature values. This behavior can be ascribed to the possible presence of a pollucite phase in the leached samples that was observed in several samples specifically prepared to investigate the incorporation of the sole Cs (Section 3.1). Similar considerations can be made for SAP-based matrices. Only a few literature results were found concerning the SAP matrix blended with borosilicate glass, while no results were found for SAP blended with glass frit. According to the collected data, the here studied CSW.SAP.BG matrix exhibits lower retention properties with respect to similar matrices studied by Park et al. $[27,35]$. Differences in the borosilicate glass composition utilized in the matrices preparation could be responsible of this discrepancy, in particular taking into account that in the present study a commercial BG was used without any optimization of the glass composition.

CSW.SAP.GF, which is the matrix that better behaves among the ones studied in this work, shows leaching performances close to those reported in the literature. It is worth noting that both the SAP-based matrices here studied show very low normalized 


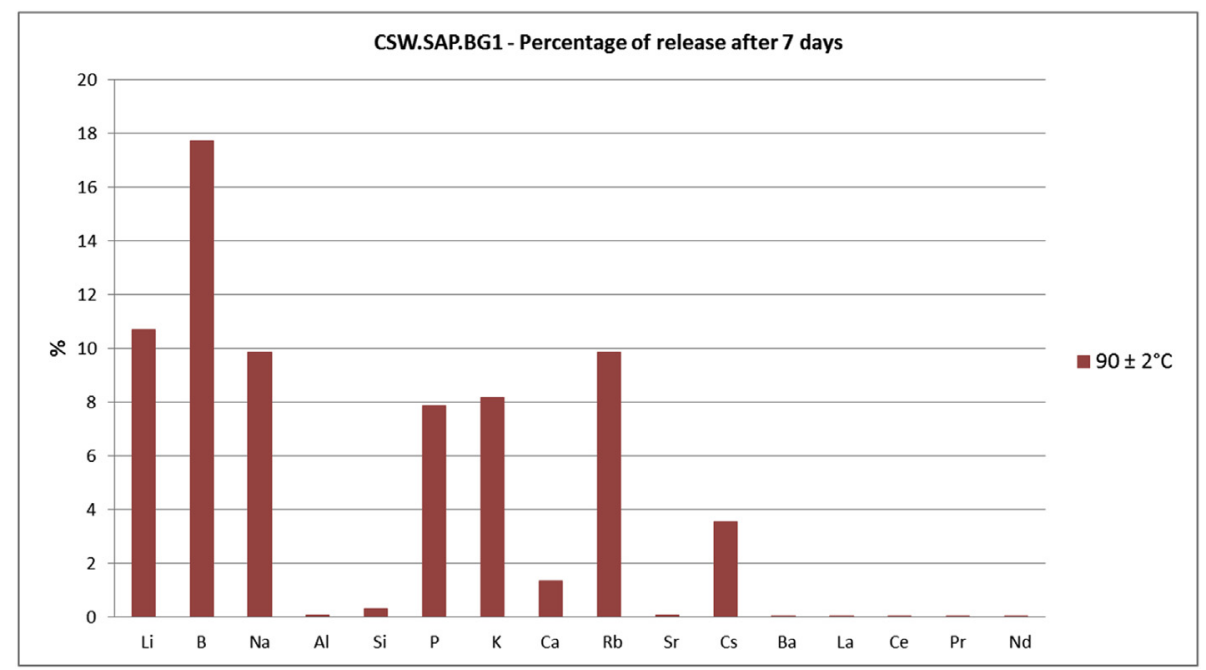

Fig. 22. CSW.SAP.BG1 leaching tests. Percentage of release after 7 days at $90 \pm 2{ }^{\circ} \mathrm{C}$.

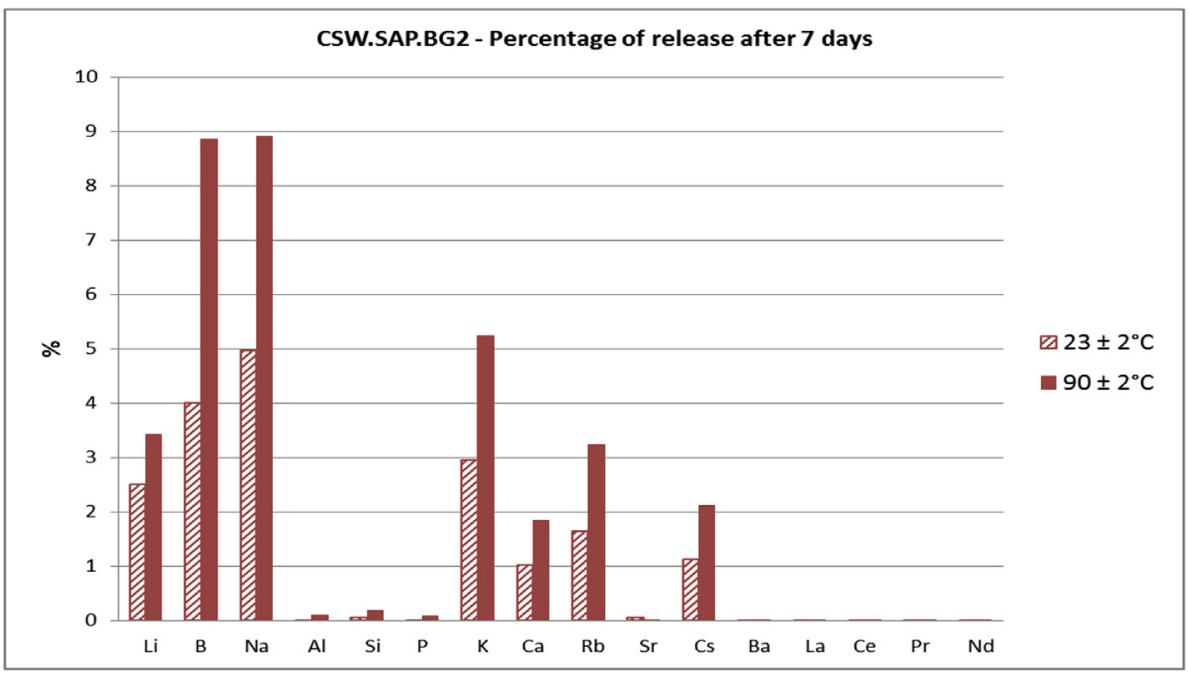

Fig. 23. CSW.SAP.BG2 leaching tests. Percentage of release after 7 days at $23 \pm 2{ }^{\circ} \mathrm{C}$ and at $90 \pm 2{ }^{\circ} \mathrm{C}$.

releases for some fission products (Ba, La, Ce, Pr and $\mathrm{Nd}$ ) whose PCT-leachability from SAP based matrices is poorly reported in literature and thus comparisons regarding these elements cannot be here discussed.

CSW.SAP.GF leaching data are also of the same order of magnitude of results reported by Ahn et al. concerning some SAP-based matrices with different formulations [36].

In order to establish the relevance of the obtained results, a further comparison can be made in term of normalized releases after 7 days at $90{ }^{\circ} \mathrm{C}$ with the PCT leaching data related to lanthanide borosilicate glasses expressly studied for disposal of highly active waste in the Yucca Mountain Federal Repository [37]. According to Table 4, the normalized releases of the CSW.SAP.GF matrix are of the same order of magnitude or even lower if compared with the results obtained at the Savannah River National Laboratory.

It must be pointed out that in the scale-up of the SAP sintering procedure, adequate recovery systems should be adopted to capture the gaseous emissions intrinsic in SAP dechlorination process. Indeed, such gaseous emissions may contain active elements, such as Chlorine 36 which arises from irradiation of $\mathrm{Cl}-35$ impurities in the Zircaloy cladding [38]. Recovering of gaseous emissions can be performed with zeolite 4A columns, giving rise to a small amount of secondary waste that needs to be dealt with, for instance by transforming zeolite into sodalite [18].

\section{Conclusions}

The chemical properties of molten chloride salt waste arising from the recovering of uranium and plutonium through pyroprocessing of spent nuclear fuel make the direct vitrification or ceramization unfeasible. In the present work, SOD- and SAP-based matrices were evaluated as potential matrices for the confinement of chloride salt waste. To this purpose, different matrices loaded with simulated chloride salt waste and blended with glass were prepared, properly characterized and leached at ambient temperature and at $90{ }^{\circ} \mathrm{C}$ up to 150 days.

The results showed that the release increases, as expected, with increasing temperature. Moreover, it was observed that the addition of glass frit to SOD and SAP matrices enhances the matrix retention capability, thereby improving the containment properties. In particular, among the studied matrices, the SAP matrix 


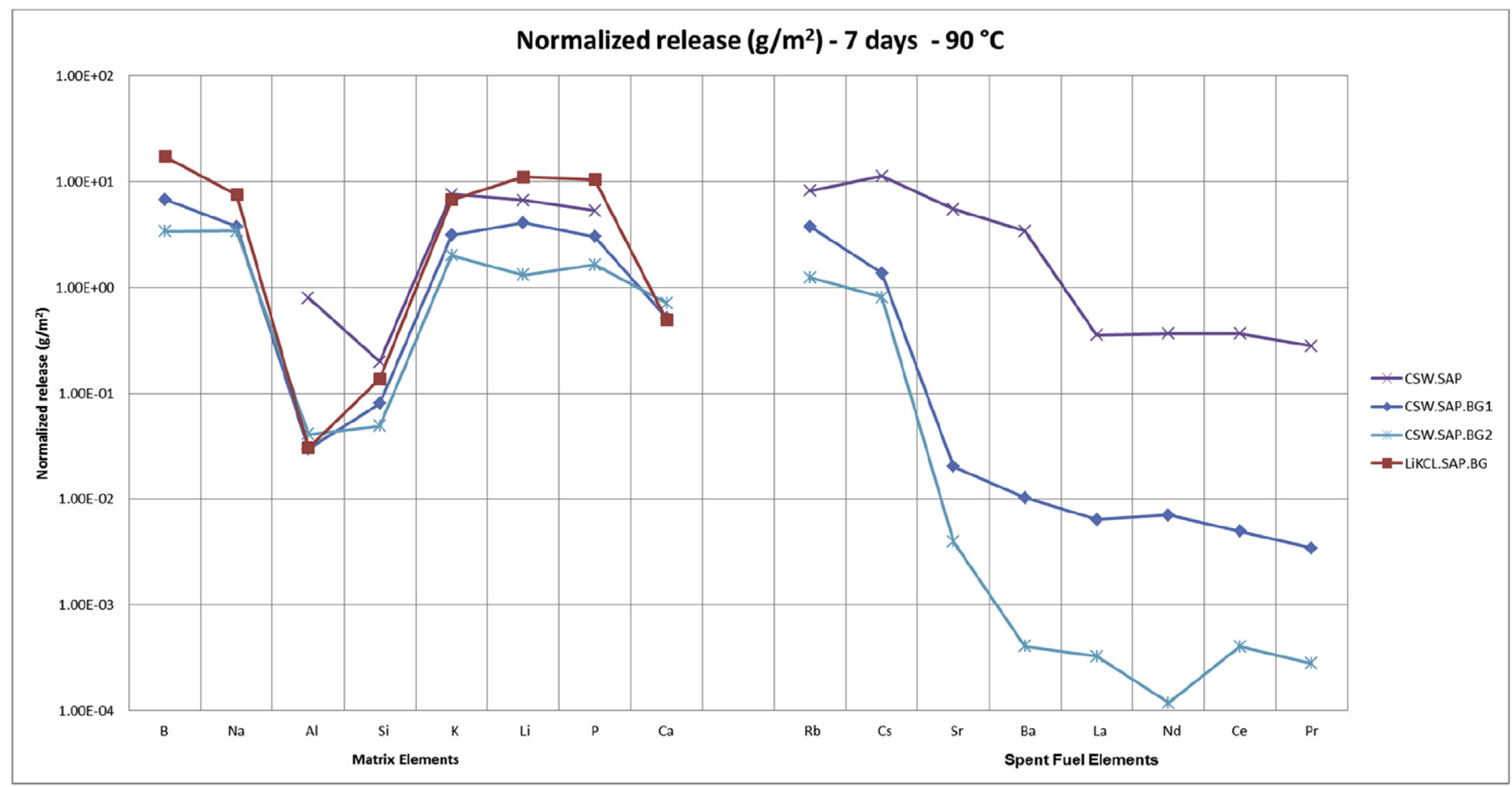

Fig. 24. Comparison of normalized release of SAP and SAP-BG samples after 7 days at $90{ }^{\circ} \mathrm{C}$.

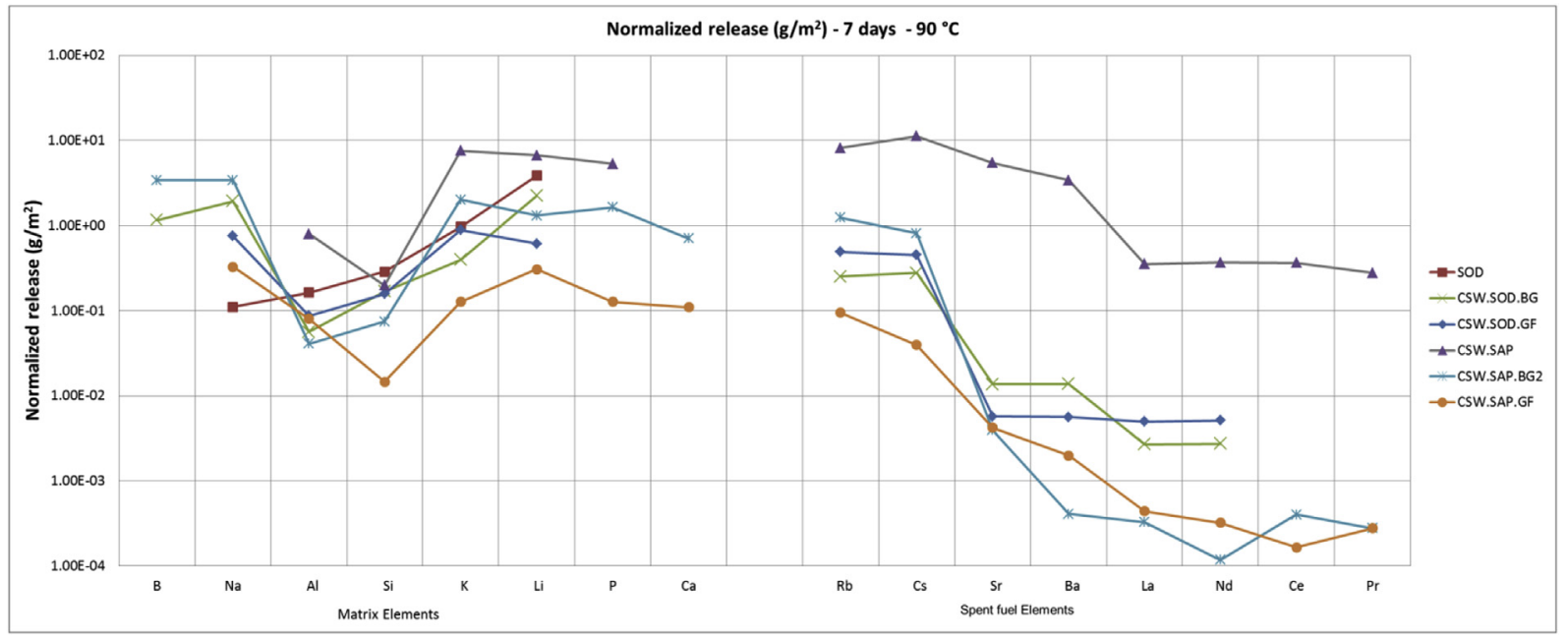

Fig. 25. Normalized release after 7 days at $90{ }^{\circ} \mathrm{C}$ of all the samples under study.

blended with glass frit showed the best confining performances with respect to both matrix elements and spent fuel elements.

An attempt was also made to collate and summarize comparable leaching data from the literature for matrices of interest in the confinement of nuclear chloride waste. The literature review highlighted the availability of leaching data mainly expressed in terms of normalized release of matrix elements at $90{ }^{\circ} \mathrm{C}$ after 7 days. Very few data were found regarding fission products release.

According to the above comparison, the here studied SOD- and SAP- matrices blended with glass frit exhibit normalized releases of matrix elements comparable with similar results from the literature.

From the long term leaching tests performed up to 150 days, it was observed that at $90{ }^{\circ} \mathrm{C}$ normalized releases of both matrix elements and fission products increased very slowly with time from 7 to 30 days becoming almost constant from 30 to 90 days.

The normalized releases of the fission products are much lower than those of the matrix elements except for the couple $\mathrm{Rb}-\mathrm{Cs}$ whose release is notable in all the studied matrices due to their high solubility in water.

The results so far obtained suggest that the studied matrices could be feasible for the confinement of chloride salt wastes. In order to improve the retention capacity for $\mathrm{Rb}$ and $\mathrm{Cs}$ new glass formulations need to be developed and investigated.

Given that the release of the various species present in the conditioned waste is strongly influenced by external factors, such as temperature and $\mathrm{pH}$, the future experimental activities will be devoted to the evaluation of the effect of $\mathrm{pH}$ conditions. 


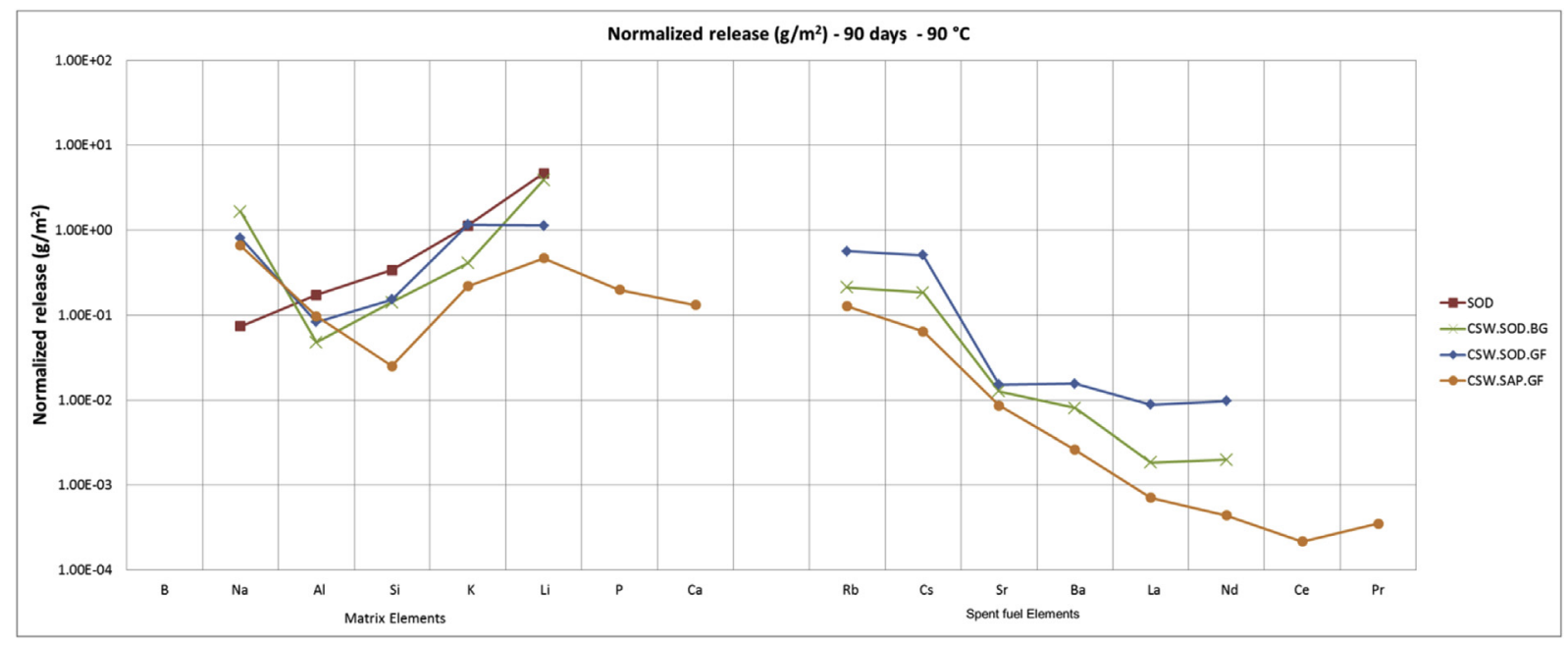

Fig. 26. Normalized release after 90 days at $90{ }^{\circ} \mathrm{C}$ of SOD, CSW.SOD.BG, CSW.SOD.GF and CSW.SAP.GF.

Table 3

Leaching test results according to PCT procedure: Normalized release $\left(\mathrm{g} \cdot \mathrm{m}^{-2}\right)$ after 7 days leaching test at $90 \pm 2{ }^{\circ} \mathrm{C}$.

\begin{tabular}{|c|c|c|c|c|c|c|c|c|c|c|c|c|}
\hline & $\begin{array}{l}\text { SOD.GF } \\
{[12]}\end{array}$ & $\begin{array}{l}\text { SOD.GF } \\
\text { HIP method } \\
*[11] \\
* *[13]\end{array}$ & $\begin{array}{l}\text { SOD.BG } \\
\text { PC method } \\
{[15]}\end{array}$ & $\begin{array}{l}\text { SOD } \\
\text { This study }\end{array}$ & $\begin{array}{l}\text { CSW.SOD.GF } \\
\bullet[24] \\
+[25]\end{array}$ & $\begin{array}{l}\text { CSW.SOD.BG } \\
\text { This study }\end{array}$ & $\begin{array}{l}\text { CSW.SAP.BG } \\
\text { SAP } 125 \text { [27] }\end{array}$ & $\begin{array}{l}\text { CSW.SAP } \\
\text { This study }\end{array}$ & $\begin{array}{l}\text { CSW.SAP.GF } \\
\text { This study, } \\
+[25]\end{array}$ & $\begin{array}{l}\text { CSW.SAP.BG1 } \\
\text { This study }\end{array}$ & $\begin{array}{l}\text { CSW.SAP.BG2 } \\
\text { This study, } \\
\text { • [30] }\end{array}$ & $\begin{array}{l}\text { LiKCl.SAP.BG } \\
\text { This study }\end{array}$ \\
\hline $\mathrm{Li}$ & 0.45 (HIP) 0.66 (PC) & $0.32^{* *}$ & 0.59 & 3.86 & $0.61 \bullet+$ & 2.23 & 0.84 & 6.67 & $0.31+$ & 4.09 & $1.31 \bullet \bullet$ & 11.1 \\
\hline B & 0.38 (HIP) 0.25 (PC) & $0.10^{* *}$ & 0.14 & & & 1.16 & 0.99 & & & 6.78 & 3.39 & 17.4 \\
\hline $\mathrm{Na}$ & & $0.28^{* *}$ & 0.39 & 0.11 & $0.75 \bullet+$ & 1.74 & 0.11 & & $0.33+$ & 3.78 & $3.41 \bullet \bullet$ & 7.55 \\
\hline $\mathrm{Al}$ & 0.097 (HIP) 0.06 (PC) & $0.029^{* *}$ & 0.045 & 0.16 & $0.087 \bullet+$ & 0.052 & 0.059 & 0.799 & $0.080+$ & 0.030 & $0.041 \bullet \bullet$ & 0.030 \\
\hline $\mathrm{Si}$ & 0.09 (HIP) 0.05 (PC) & $0.034^{* *}$ & 0.047 & 0.29 & $0.157 \bullet+$ & 0.107 & 0.102 & 0.198 & $0.015+$ & 0.122 & $0.075 \bullet \bullet$ & 0.208 \\
\hline $\mathrm{P}$ & & & & & & & 0.561 & 5.32 & 0.127 & 3.01 & 1.64 & 10.4 \\
\hline K & & $0.18^{*}$ & 0.23 & 0.96 & $0.89 \bullet+$ & 0.38 & & 7.57 & $0.13+$ & 3.13 & $2.00 \bullet \bullet$ & 6.70 \\
\hline $\mathrm{Ca}$ & & & & & & & 0.041 & & 0.11 & 0.51 & 0.71 & 0.49 \\
\hline $\mathrm{Rb}$ & & & & & $0.49+$ & 0.25 & & 8.16 & $0.09+$ & 3.77 & 1.24 & \\
\hline $\mathrm{Sr}$ & & & & & $0.006+$ & 0.014 & 0.012 & 5.46 & $0.004+$ & 0.020 & $0.004 \bullet \bullet$ & \\
\hline Cs & & $1.13^{*}$ & & & $0.451+$ & 0.279 & 0.0098 & 11.3 & $0.0395+$ & 1.36 & $0.811 \bullet \bullet$ & \\
\hline $\mathrm{Ba}$ & & & & & $0.0056+$ & 0.0137 & & 3.42 & $0.0020+$ & 0.0103 & 0.0004 & \\
\hline $\mathrm{La}$ & & & & & $0.00496+$ & 0.00270 & & 0.354 & $0.00044+$ & 0.00639 & 0.00033 & \\
\hline $\mathrm{Ce}$ & & & & & & & & 0.366 & 0.00017 & 0.0050 & 0.00040 & \\
\hline $\operatorname{Pr}$ & & & & & & & & 0.279 & 0.00028 & 0.00343 & 0.00028 & \\
\hline $\mathrm{Nd}$ & & & & & $0.00513+$ & 0.00275 & & 0.367 & $0.00032+$ & 0.00703 & 0.00012 & \\
\hline
\end{tabular}

Table 4

Normalized release $\left(\mathrm{g} \cdot \mathrm{m}^{-2}\right)$ after 7 days leaching test at $90 \pm 2{ }^{\circ} \mathrm{C}$.

\begin{tabular}{lll}
\hline & Pu Frit B & $\begin{array}{l}\text { CSW.SAP.GF } \\
{[25]}\end{array}$ \\
\hline $\mathrm{Si}$ & {$[37]$} & 0.015 \\
$\mathrm{Sr}$ & $<0.0098$ & 0.004 \\
$\mathrm{La}$ & 0.011 & 0.00044 \\
$\mathrm{Nd}$ & 0.00046 & 0.00032 \\
\hline
\end{tabular}

\section{Acknowledgements}

This work was supported by the Nuclear Fission Safety Program of the European Union (project ACSEPT, contract FP7-CP-2007-211 267; project SACSESS, contract FP7-CP-2012-323282). The authors gratefully acknowledge the 'Micro and Nanostructured Materials Lab' of NEMAS-Department of Energy - Politecnico di Milano for SEM analyses. Special thanks to A. Mantegazza for his support in the experimental activity.

\section{Appendix A. Supplementary data}

Supplementary data related to this article can be found at https://doi.org/10.1016/j.jnucmat.2017.11.051.

\section{References}

[1] T. Nishimura, T. Koyama, M. Iizuka, H. Tanaka, Development of an environmentally benign reprocessing technology - Pyrometallurgical reprocessing technology, Prog. Nucl. Energ 32 (3/4) (1998) 381-387.

[2] J.-H. Yoo, J.-K. Kim, H.-S. Lee, I.-S. Seo, E.-ka. Kim, Patent analysis for pyroprocessing of spent nuclear fuel, J. Nucl. Fuel Cycle Waste Technol 9 (4) (2011) 247-258.

[3] H.F. McFarlane, K.M. Goff, F.S. Felicione, C.C. Dwight, D.B. Barber, Hot demonstrations of nuclear-waste processing technologies, JOM 49 (7) (1997) 14-21.

[4] J.P. Ackerman, T.R. Johnson, L.S.H. Chow, E.L. Carls, W.H. Hannum, J.J. Laidler Treatment of wastes in the IFR fuel cycle, Progr. Nucl. Energ 31 (1/2) (1997) $141-154$.

[5] S.D. Herrmann, S.X. Li, M.F. Simpson, S. Phongikaroon, Electrolytic reduction of spent nuclear oxide fuel as part of an integral process to separate and recover actinides from fission products, Sep. Sci. Technol. 41 (2006) 1965-1983.

[6] S. Siwadamrongpong, M. Koide, K. Matusita, Prediction of chloride solubility in $\mathrm{CaO}-\mathrm{Al}_{2} \mathrm{O}_{3}-\mathrm{SiO}_{2}$ glass systems, J. Non-Cryst. Solids 347 (2004) 114-120. 
[7] M.G. Mesko, D.E. Day, Immobilization of spent nuclear fuel in iron phosphate glasses, J. Nucl. Mater 273 (1999) 27-36.

[8] B.L. Metcalfe, I.W. Donald, Candidate wasteforms for the immobilization of chloride-containing radioactive wastes, J. Non-Cryst. Solids 348 (2004) 225-229. https://doi.org/10.1016/j.jnoncrysol.2004.08.173.

[9] G. Leturcq, A. Grandjean, D. Rigaud, P. Perouty, M. Charlot, Immobilization of fission products arising from pyrometallurgical reprocessing in chloride media, J. Nucl. Mater 347 (2005) 1-11.

[10] M. A. Lewis, C. Pereira, Method of preparing sodalite from chloride salt occluded zeolite, United States Patent 5613240, March 18, 1997.

[11] M.A. Lewis, W.L. Ebert, M. Stanley, Corrosion behaviors of glass-bonded sodalite ceramic waste form and its constituents, in: Global '99 Conference, Jackson Hole, WY. August 29- September 3, 1999.

[12] T.J. Battisti, K.M. Goff, K.J. Bateman, M.F. Simpson, J.P. Lind, Ceramic waste form production and development at ANL-West, in: American Nuclear Society Fifth Topical Meeting, Charleston, SC, September 17-20, 2002.

[13] M.A. Lewis, M.C. Hash, A. Hebden, W.L. Ebert, Tests with Ceramic Waste Form Materials Made by Pressureless Consolidation, Argonne National Laboratory Report ANL 02/10, 2002.

[14] S.-Y. Jeong, L.R. Morss, W.L. Ebert, Corrosion of glass-bonded sodalite and its components as a function of $\mathrm{pH}$ and temperature, Scientific basis for nuclear waste management XXV, in: Materials Research Society Fall Meeting, Boston, MA. November 26-30, 2001.

[15] S. Priebe, K. Bateman, The ceramic waste form process at Idaho National Laboratory, Nucl. Technol. 162 (2008) 199-207.

[16] E.R. Vance, J. Davis, K. Olufson, I. Chironi, I. Karatchevtseva, I. Farnan, Candidate waste forms for immobilisation of waste chloride salt from pyroprocessing of spent nuclear fuel, J. Nucl. Mat. 420 (2012) 396-404.

[17] B.J. Riley, J.D. Vienna, S.M. Frank, J.O. Kroll, J.A. Peterson, N.L. Canfield, Z. Zhu, J. Zhang, K. Kruska, D.K. Schreiber, J.V. Crum, Glass binder development for a glass-bonded sodalite ceramic waste form, J. Nucl. Mat. 489 (2017) 42-63.

[18] L.R. Morss, M.A. Lewis, M.K. Lichmann, D. Lexa, Cerium, uranium, and plutonium behavior in glass-bonded sodalite, a ceramic nuclear waste form, J. Alloys Compd. 303-304 (2000) 42-48.

[19] M.J. Lambreghts, S.T. Frank, Characterization of cesium containing glassbonded ceramic waste forms, Micropo. Mesopo. Mat. 64 (2003) 1-9.

[20] T. Koyama, C. Matsubara, T. Sawa, H. Tanaka, Waste form development for immobilization of radioactive halide salt generated from pyro-metallurgical reprocessing, in: Proceedings from GLOBAL 1997, vol. 1, 1997, pp. 610-615.

[21] G. De Angelis, R. Nannicini, F. Martini, C. Mazzocchia, G. Modica, Differen methods to synthesize sodalite as a matrix for conditioning chloride spent salts from pyroprocessing, Radiochim. Acta 96 (2008) 303-310.

[22] G. De Angelis, I. Bardez-Giboire, M. Mariani, M. Capone, M. Chartier, E. Macerata, Synthesis and characterization of sodalite as matrix for conditioning chloride spent salts from pyroprocesses, Material Res. Soc. Symposium Proc. 1193 (2009) 73-78.

[23] G. De Angelis, C. Fedeli, A. Manniello, M. Da Ros, F. Giacobbo, E. Macerata M. Mariani, Conditioning of chloride salt wastes from pyroprocesses through the pressureless consolidation process, ATALANTE 2012 International conference on nuclear chemistry for sustainable fuel cycles, Procedia Chem. 7 (2012) 746-753.

[24] M. Capone, G. De Angelis, C. Fedeli, F. Giacobbo, M. Da Ros, E. Macerata, M. Mariani, Leaching behavior of salt wastes conditioned with sodalite blended with two different glass powders, Adv. Sci. Technol. 94 (2014)
131-136, https://doi.org/10.4028/www.scientific.net/AST.94.131.

[25] G. De Angelis, E. Baicchi, M. Capone, C. Fedeli, M. Sepielli, G. Tiranti, M. Da Ros, F. Giacobbo, M. Giola, E. Macerata, M. Mariani, Pyroprocess experiments at ENEA laboratories, J. Nucl. Fuel Cycle Waste Technol. 13 (S) (2015) 19-27. https://doi.org/10.7733/jnfcwt.2015.13.S.19 .

[26] M. Capone, C. Fedeli, G. De Angelis, M. Da Ros, F. Giacobbo, M. Giola, E. Macerata, M. Mariani, A study on sodalite pellets as matrix for spent chloride salts confinement, MRS Adv. Mater. Res. Soc. (2017), https://doi.org/ 10.1557/adv.2017.218

[27] H.-S. Park, I.-T. Kim, Y.-Z. Cho, H.-C. Eun, H.-S. Lee, Stabilization/solidification of radioactive salt waste by using $\mathrm{xSiO}_{2}-\mathrm{yAl}_{2} \mathrm{O}_{3}-\mathrm{zP}_{2} \mathrm{O}_{5}$ (SAP) material at molten salt state, Environ. Sci. Technol. 42 (2008) 9357-9362. https://doi.org/ 10.1021/es802012x.

[28] I.H. Cho, H.-S. Park, S.N. Ahn, I.-T. Kim, Y. Z, Cho, Stabilization/solidification of radioactive $\mathrm{Li}-\mathrm{Cl}-\mathrm{KCl}$ waste salt by using $\mathrm{SiO}_{2}-\mathrm{Al}_{2} \mathrm{O}_{3}-\mathrm{P}_{2} \mathrm{O}_{5}$ (SAP) inorganic composite: Part 1. Dechlorination behavior of $\mathrm{LiCl}-\mathrm{KCl}$ and characteristics of consolidation, J. Korean Radioact. Waste Soc. 10 (1) (2012) 45-53.

[29] G. De Angelis, M. Capone, C. Fedeli, G. Marzo, M. Mariani, E. Macerata, M. Giola, A new matrix for conditioning chloride salt wastes from the electrorefining of spent nuclear fuel, Adv. Sci. Technol 94 (2014) 97-102, https:// doi.org/10.4028/www.scientific.net/AST.94.97.

[30] G. De Angelis, C. Fedeli, M. Capone, G.A. Marzo, M. Mariani, M. Da Ros, F. Giacobbo, E. Macerata, M. Giola, Different Methods for Conditioning Chloride Salt Wastes, Actinide and Fission Product Partitioning and Transmutation - Thirteen Information Exchange Meeting, 2015. Seoul, Republic of Korea, 23-26 September 2014. Nuclear Energy Agency NEA/NSC/R(2015)2.

[31] S.N. Ahn, H.S. Park, I.H. Cho, I.T. Kim, Y.Z. Cho, Stabilization/solidification of radioactive $\mathrm{Li}-\mathrm{Cl}-\mathrm{KCl}$ waste salt by using $\mathrm{SiO}_{2}-\mathrm{Al}_{2} \mathrm{O}_{3}-\mathrm{P}_{2} \mathrm{O}_{5}$ (SAP) inorganic composite: Part 2. The effect of SAP composition on stabilization/solidification, J. Korean Radioact. Waste Soc. 10 (1) (2012) 27-36.

[32] N.-Y. Kim, I.H. Cho, H.-S. Park, D.-H. Ahn, Dechlorination/solidification of LiCl waste by using a synthetic inorganic composite with different compositions, J. Nucl. Fuel Cycle Waste Technol 14 (3) (2016) 211-221 https://doi.org/10. 7733/jnfcwt.2016.14.3.211.

[33] M. Laczka, M. Cienciska, Preparation, structure and properties of silicatephosphate glasses obtained by means of sol-gel method, J. Sol-Gel Sci. Techn 3 (1994) 219-227.

[34] ASTM C1285-02, Standard Test Methods for Determining Chemical Durability of Nuclear, Hazardous and Mixed Waste Glasses and Ceramics: the Product Consistency Test (PCT), Reapproved 2008.

[35] H.-S. Park, I.-H. Cho, H.C. Eun, I.-T. Kim, Y.Z. Cho, H.-S. Lee, Characteristics of wasteform composing of phosphate and silicate to immobilize radioactive waste salts, Environ. Sci. Technol. 45 (2011) 1932-1939.

[36] B.-G. Ahn, H.-S. Park, I.-T. Kim, H.-S. Lee, Solidification of Ln oxides containing volatile chlorides from pyrochemical process, Nucl. Technol. 173 (3) (2011) 300-309.

[37] C.L. Crawford, J.C. Marra, N.E. Bibler, Glass fabrication and product consistency testing of lanthanide borosilicate glass for plutonium disposition, Savannah River National Laboratory, Aiken, SC, 2007, 29808, USA. WSRCSTI-2007-00079, Rev.0.

[38] L.H. Baetsle, Application of partitioning/transmutation of radioactive Materials in radioactive waste management, in: N. Paver (Ed.), (INIS-XA-900), International Atomic Energy Agency (IAEA), 2003. 